\title{
GSH Induced Controlled Release of Levofloxacin form a Purpose-built Prodrug: Luminescence Response for Probing the Drug Release in E-coli and Staphylococcus aureus
}

Suman Pal, ${ }^{\dagger}$ Vadde Ramu, ${ }^{\dagger}$ Nandaraj Taye, ${ }^{\ddagger}$ Devraj G. Mogare, ${ }^{\ddagger}$ Amar M Yeware, ${ }^{\dagger}$ Dhiman Sarkar, ${ }^{+*}$ D. Srinivasa Reddy, ${ }^{+*}$ Samit Chattopadhyay, ${ }^{\ddagger}, \boldsymbol{I}^{*}$ and Amitava Das ${ }^{\dagger, \# *}$

${ }^{\dagger}$ Organic Chemistry Division, CSIR-National Chemical Laboratory, Dr. Homi Bhabha Road, Pune: 411008, Maharashtra, India. E-mail: ds.reddy@ncl.res.in, d.sarkar@ncl.res.in

"Indian Institute of Chemical Biology, 4, Raja S. C. Mullick Road, Jadavpur, Kolkata- 700032, Email: samit@iicb.res.in

\#Analytical Science, CSIR-Central Salt and Marine chemical Research Institute, Gijubhai Badheka Marg, Bhavnagar-364002, India, Fax:+912782577562, Email: a.das@csmcri.org.

${ }^{\ddagger}$ Chromatin and Disease Biology Lab; National Centre for Cell Science; Ganeshkhind, Pune 411007, India. 
- General experimental procedure S3-S4

- General procedure for checking MIC value S5

- Table for MIC S5

- General procedure for CFU study S6

- Table for time dependent CFU study S6

- Plot for time dependent CFU study S6

- Cell viability assay, procedure of cell culture and cell imaging

- HPLC seperation method S9-S10

- Lipophilicity mesurement

- Qunatum yield measurement procedure

- ROESY corelation S13

- Graph of MTT assay S14

- Deconvolution spectra of L, LSSTr (PD1), LSSDMTr (PD2) S15

- ${ }^{1} \mathrm{H}$ NMR TrSSOH S16

- HRMS, ${ }^{1} \mathrm{H}$ and ${ }^{13} \mathrm{C}$ NMR of PD1 (LSSTr)

- ${ }^{13}$ C, DEPT, COSY, HSQC, HMBC and ROESY NMR of LSSTR in DMSO-D $_{6}$

- HRMS, ${ }^{1} \mathrm{H}$ and ${ }^{13} \mathrm{C}$ NMR of PD2 (LSSDMTr)

S25-S27

- HPLC plots of fragment seperations from the reaction mixture

- HPLC chromatograms for kinetic study

- ${ }^{1} \mathrm{H}, \mathrm{D}_{2} \mathrm{O}$ treatment with ${ }^{1} \mathrm{H},{ }^{13} \mathrm{C}$, DEPT and HRMS of hydroxy trityl fragment

- ${ }^{1} \mathrm{H}$ and HRMS of intermediate1 [l],

- ${ }^{1} \mathrm{H}$ and HRMS of Levofloxacin after fragmentation

- Plot for pearson coefficient

- Stability profile diagram of $\mathrm{PD}_{1}$ and $\mathrm{PD}_{2}$ in $\mathrm{BSA}$

- References 


\section{EXPERIMENTAL SECTION}

General experimental information: Starting materials like Levofloxacin, trityl chloride, dimethoxy trityl chloride, di-isopropyl-ethyl-amine, bis-(2-hydroxyethyl)-disulfide and solvents like dichloromethane, pyridine, hexane, ethyl acetate have been procured from Sigma Aldrich, Alfa Aesar and Rankem. For recording spectra spectroscopy grade solvent have been used. For purification of the products column chromatography has been employed using Merck 100-200 silica gel. For separation of the fragments preparative TLC plates (using PLC Silica gel $60 \mathrm{~F}_{254}, 2 \mathrm{~mm}$ plate) have been employed. ${ }^{1} \mathrm{H}{ }^{13} \mathrm{C}$, DEPT and other NMR spectra were recorded in Bruker 500, $200 \mathrm{MHz}$, Jeol $400 \mathrm{MHz}$ spectrometer. Mass and HRMS spectra were recorded in JEOL JM AX 505 HA mass spectrometer. Absorption and emission spectra of those compounds has been recorded using Cary 500 and Edinburgh instrument Xe-900 spectro fluorometer. spectrophotometer. While confocal cell images were recorded in Olympus Fluoview microscope instrument. HPLC separation of fragments from the reaction mixture is performed by using MERCK HITACHI instrument (PUMP L-7100, UV DETECTOR L-7400) using reverse phase Kromasil column RP-18 (250 X $4.6 \mathrm{~mm}$ ).

Experimental details: Trityl-SS-OH and Dimethoxy Trityl-SS-OH are prepared according to the reported method. ${ }^{1,2}$

${ }^{1} \mathrm{H}$ NMR of trityl-SS-OH: ${ }^{1} \mathrm{H}$ NMR $\left(200 \mathrm{MHz}, \mathrm{CDCl}_{3}, \mathrm{ppm}\right), \delta$ 7.56-7.5 (m, 6H), $7.5-$ $7.23(\mathrm{~m}, 9 \mathrm{H}), 3.78(\mathrm{t}, J=6.0 \mathrm{~Hz}, 2 \mathrm{H}), 3.39(\mathrm{t}, J=6.5 \mathrm{~Hz}, 2 \mathrm{H}), 2.88(\mathrm{t}, J=6.5,2 \mathrm{H}), 2.7$ (t, $J=6.0 \mathrm{~Hz}, 2 \mathrm{H}), 1.89(\mathrm{~s}, 1 \mathrm{H})$.

${ }^{1} \mathrm{H}$ and ${ }^{13} \mathrm{C}$ NMR of Hydroxy trityl fragment: ${ }^{1} \mathrm{H}$ NMR (200 $\left.\mathrm{MHz}, \mathrm{CDCl}_{3}, \mathrm{ppm}\right), \delta 7.21$ $(\mathrm{m}, 15 \mathrm{H}), 2.7(\mathrm{~s}, 1 \mathrm{H}),{ }^{13} \mathrm{C} \mathrm{NMR}\left(100 \mathrm{MHz}, \mathrm{CDCl}_{3}, \mathrm{ppm}\right) \delta 146.8,127.9,127.3,82$. Observed HRMS peak at 243.1169 is attributed for $\mathrm{C}_{19} \mathrm{H}_{15}$.

${ }^{1} \mathrm{H}$ NMR of Hydroxy ethyl ester of Levofloxacin (intermediate1 [I]) fragment: ${ }^{1} \mathrm{H}$ NMR (200 MHz, MeOD, ppm), $\delta 8.97$ (s, 1H), 7.66 (d, $J=12.5 \mathrm{~Hz}, 1 \mathrm{H}), 4.6(\mathrm{~m}, 3 \mathrm{H}), 3.43$ 
(m, 8H), $2.7(\mathrm{~m}, 4 \mathrm{H}), 2.44(\mathrm{~s}, 3 \mathrm{H}), 1.57(\mathrm{~d}, J=6.8 \mathrm{~Hz}, 3 \mathrm{H})$. Observed HRMS peak at 421.1455 is attributed for $\mathrm{C}_{20} \mathrm{H}_{24} \mathrm{O}_{4} \mathrm{~N}_{3} \mathrm{FS}$ is attributed for (intermediate $1+\mathrm{H}$ ).

${ }^{1} \mathrm{H}$ NMR of Levofloxacin fragment. ${ }^{1} \mathrm{H}$ NMR (200 MHz, MeOD, ppm), $\delta 8.7$ (s, 1H), $7.53(\mathrm{~d}, J=12,1 \mathrm{H}), 4.47-4.43(\mathrm{~m}, 3 \mathrm{H}), 3.33(\mathrm{~m}, 4 \mathrm{H}), 2.57(\mathrm{~m}, 4 \mathrm{H}), 2.31(\mathrm{~s}, 3 \mathrm{H}), 1.45$ $(\mathrm{d}, J=6,3 \mathrm{H})$. Observed HRMS peak at 362.1505 is attributed for $\mathrm{C}_{18} \mathrm{H}_{21} \mathrm{O}_{4} \mathrm{~N}_{3} \mathrm{~F}(\mathrm{M}+\mathrm{H})$. 


\section{Antibacterial activity:}

\section{Experimental Procedure:}

E.coli and Staphylococcus aureus cultures were obtained from NCIM, Pune. Culture was grown in Lb broth (High media). Dose response effect of drug on growth was calculated by measuring the absorbance of the culture at $620 \mathrm{~nm}$ after an incubation at $37^{\circ} \mathrm{C}$.

MIC were determined by calculating percent inhibition using following formula, $\%$ inhibition $=[($ O.D. of control - O.D. of test $) /($ O.D. of control - O.D. of blank $)] \times 100$ where, control is bacteria without drug, test is growth of bacteria in presence of drug and blank is culture medium without bacteria.

The experiment was performed in triplicate and the quantitative value was expressed as the mean \pm standard deviation (S.D.).

Fluorescence Imaging were done by adding $1 \mu \mathrm{M}$ concentration of LSS, PD1, PD2 in exponential growing E.coli culture was previously incubated with GSH for $15 \mathrm{~min}$. At defined time point smear was prepared over air drying and heat fixing and images were taken by using fluorescent microscope (EVOS FL microscope, PEQLAB Ltd, UK).

Table S1. In vitro antibacterial activity of LSSTr, LSSDMTr and their GSH combination against gram positive and gram negative bacteria (MIC in $\mu \mathrm{g} / \mathrm{mL}$ ) Where concentration of GSH used in combination with the derivatives of drug were 10 times more than drug concentration.

\begin{tabular}{|l|l|l|}
\hline Compound & Staphylococcus aureus & E.coli \\
\hline & MIC in $\mu \mathrm{M}$ & MIC in $\mu \mathrm{M}$ \\
\hline GSH & $>1000$ & $>1000$ \\
\hline LSSTr & 5.1 & 6.24 \\
\hline LSSDMTr & 97.97 & $>100$ \\
\hline Levo & $<0.78$ & $<0.78$ \\
\hline GSH-Levo & $<0.78$ & $<0.78$ \\
\hline GSH-LSSTr & 2.14 & 1.37 \\
\hline GSH-LSSDMTr & 7.2 & 1.03 \\
\hline
\end{tabular}

The experiment was performed in triplicate and the quantitative value was expressed as the mean \pm standard deviation (S.D.). 


\section{MIC validation by CFU:}

To validate the MIC concentration for each drug, CFU were determined as per described in "material and methods". Levofloxacin without and with GSH showed maximum inhibition of growth (7.24 and $7.48 \mathrm{log}$ difference respectively). PD1 without GSH showed (1.7 log difference) whereas it's seen that increased growth inhibition along with GSH (3.3 log). There was not significant growth inhibition achieved by PD2 (0.39 log), but when it was incubated along with GSH maximum growth inhibition observed (7.24 log difference). GSH was not showed inhibition Staphylococcus aureus. (fig. 1).

Table S2. Time dependent colony formation study with Staphylococcus aureus using Levofloxacin, PD1 combined with 10 equiv. GSH and PD2 combined with 10 equiv. GSH (MIC concentration was used).

\begin{tabular}{|l|c|c|c|c|r|r|}
\hline & \multicolumn{4}{|c|}{$\log _{\mathbf{1 0}} \mathbf{C F U} / \mathbf{m l}$} & \multicolumn{1}{c|}{ Total no of colony } \\
\hline $\begin{array}{l}\text { time } \\
(\mathrm{hrs})\end{array}$ & Control & Levofloxacin & Pd1 & PD2 & PD1 & PD2 \\
\hline 0 & 5.444045 & 5.444045 & 5.444045 & 5.444045 & 278000.1 & 278000.1 \\
\hline 1 & 5.584331 & 5.507856 & 5.499687 & 5.553883 & 315999.9 & 358000 \\
\hline 2 & 6.474216 & 6.120574 & 6.25042 & 6.274158 & 1780000 & 1880001 \\
\hline 3 & 7.49693 & 5.845098 & 6.274158 & 6.287802 & 1880001 & 1940001 \\
\hline 4 & 9.428135 & 5.060698 & 5.456366 & 5.225309 & 286000 & 167999.9 \\
\hline
\end{tabular}

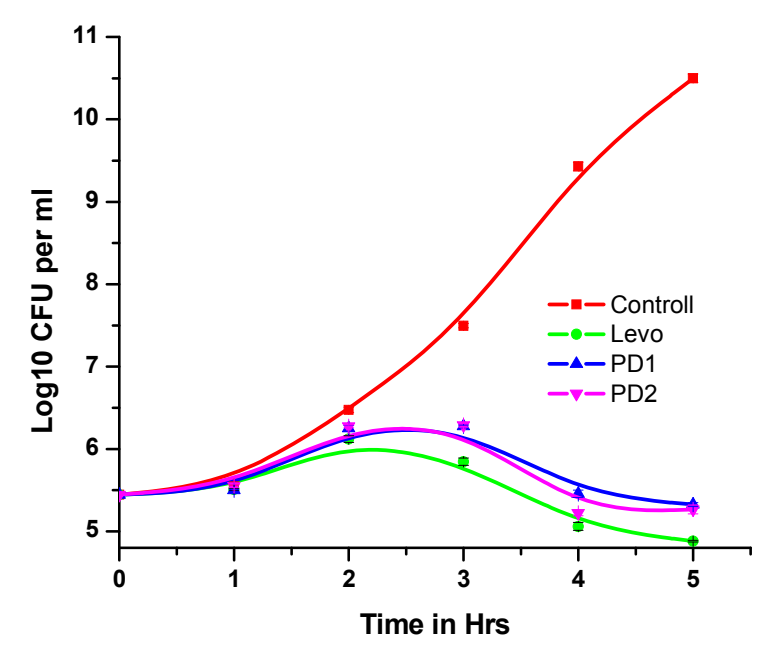

Figure S1. Plot of time dependent CFU study, When Staphylococcus aureus bacterial colonies treated with of drug Levofloxacin (green line), $\mathrm{PD}_{1}-\mathrm{GSH}$ (blue line), $\mathrm{PD}_{2}-\mathrm{GSH}$ (pink line) and without any additives (red line) which is indicative of slightly controlled release of drug Levofloxacin from $\mathrm{PD}_{1}$ an $\mathrm{PD}_{2}$. 


\section{Cell viability assay.}

The cell viability of prodrug 1, prodrug 2 and Levofloxacin has been examined thoroughly using A549 cells by MTT assay. Cells were treated with $0-1500 \mu \mathrm{M}$ solutions of prodrug 1, 2 and with Levofloxacin (final medium composition $=90 \%$ cell media, $10 \% \mathrm{FBS}$ ) for $24 \mathrm{~h}$ followed by the addition of $0.5 \mathrm{mg} / \mathrm{ml}$ of MTT reagent with $4 \mathrm{~h}$ incubation time. MTT (3-(4,5dimethylthiazol-2-yl)-2,5-diphenyltetrazolium bromide) dissolved in PBS at 5mg/ml. After finishing $4 \mathrm{~h}$ incubation time the media was removed and the formazan product was dissolved using isopropanol followed by absorbance reading at $570 \mathrm{~nm}$. An average absorbance for each concentration was obtained and the metabolic activity of the cell population was determined as a percentage against untreated negative control. IC50 values for the entire three compounds are as follows, $1210 \mu \mathrm{M}$ for prodrug $1,1360 \mu \mathrm{M}$ for prodrug 2 and $900 \mu \mathrm{M}$ (see figure 1) for the drug Levofloxacin. So the toxicity of prodrug 1 and prodrug 2 is less than the drug itself. For each independent experiment, the assays were performed in six replicates and also statistical mean and standard deviation were used to estimate the cell viability.

Table S3. Table of MTT assay.

\begin{tabular}{|l|l|l|l|l|l|l|}
\hline Control & Levofloxacin & Std. deviation & LSSTr & Std. deviation & LSSDMTr & Std. deviation \\
\hline $0 \mu \mathrm{M}$ & 100 & 0 & 100 & 0 & 100 & 0 \\
\hline $1 \mu \mathrm{M}$ & 97.432 & 3.552783 & 98.92617 & 0.881932 & 98.97463 & 0.713732 \\
\hline $10 \mu \mathrm{M}$ & 93.50053 & 3.848848 & 95.325 & 0.6355 & 96.3326 & 0.6097 \\
\hline $100 \mu \mathrm{M}$ & 82.21893 & 0.783315 & 87.699 & 3.134847 & 89.21943 & 0.91643 \\
\hline $500 \mu \mathrm{M}$ & 61.536 & 1.0256 & 1.0256 & 2.682293 & 74.18017 & 0.653304 \\
\hline $1000 \mu \mathrm{M}$ & 47.1776 & 1.356741 & 57.195 & 4.853711 & 61.5797 & 1.613115 \\
\hline $1500 \mu \mathrm{M}$ & 32.8192 & 4.945264 & 40.0365 & 0.733812 & 44.91457 & 2.154018 \\
\hline
\end{tabular}

\section{Cell culture and cell imaging.}

A549 cells (human non-small lung cancer cell) and Hct116 (Colon cancer cells) were cultured in DMEM medium supplemented with $10 \%$ fetal bovine serum (FBS) and 100 units of penicillin-streptomycin antibiotics at $37^{\circ} \mathrm{C}$ under a humidified atmosphere containing $5 \% \mathrm{CO}_{2}$. 
One day before imaging process, cells were cultured on cover slips inside $35 \mathrm{~mm}$ petridishes and allowed to grow to $50-70 \%$ confluence. Then cells grown on cover-slips were incubated in DMEM medium containing prodrug 2 and drug Levofloxacin (100 $\mu \mathrm{M})$ at $37^{\circ} \mathrm{C}$ under $5 \% \mathrm{CO}_{2}$ for $10 \mathrm{~min}$ to $2 \mathrm{~h}$. Afterwards, the cells on cover-slips were washed with PBS for three times and then mounted onto glass slides using mounting medium. Imaging was done using Olympus Fluoview microscope. Same procedure was followed for ER tracker green then images are superimposed for colocalization study.

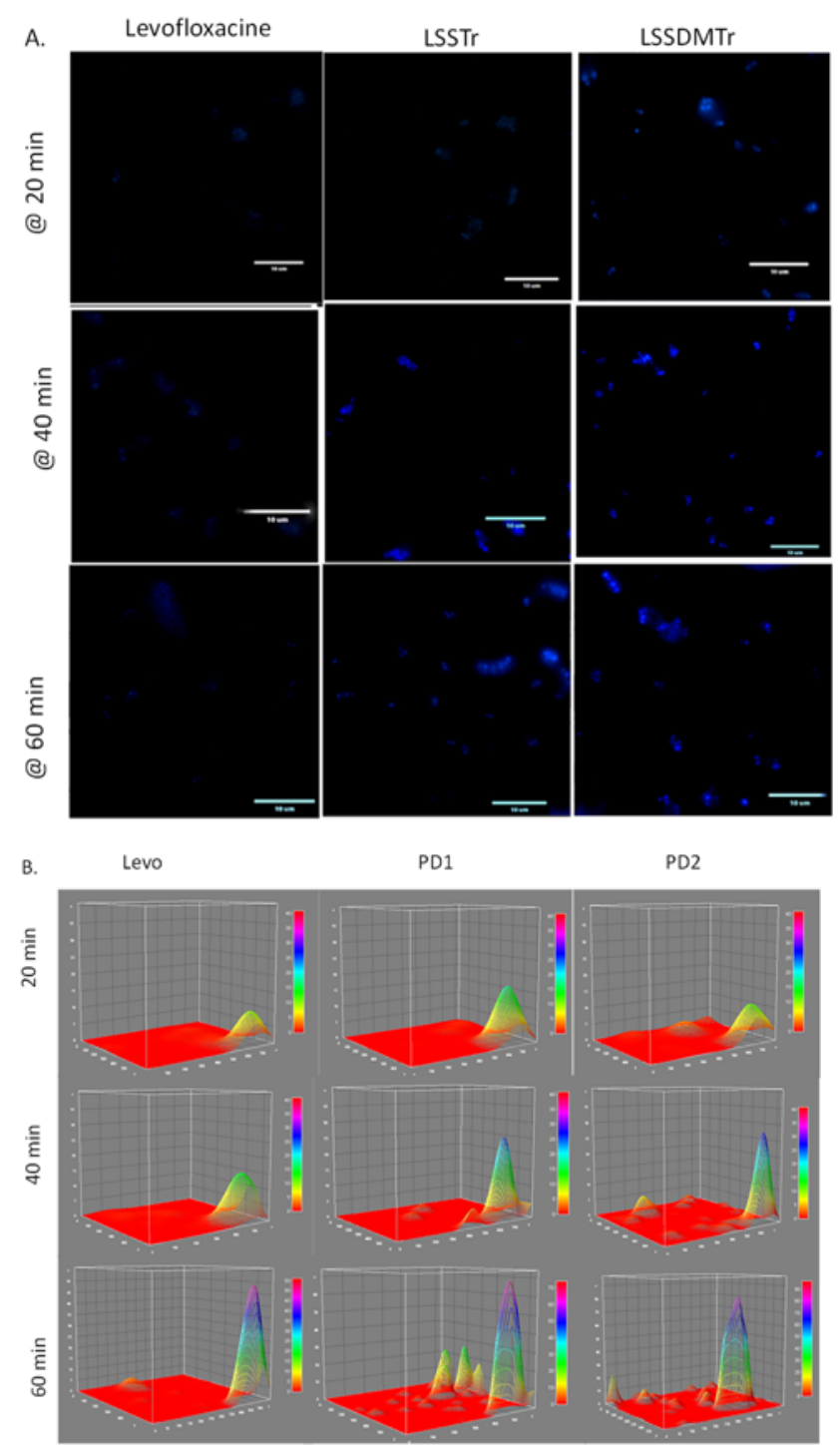

Figure S2. Kinetics study of intake prodrugs and concomitant release of drugs by GSH which is also incubated before prodrug incubation in Staphylococcus aureus. The fluorescence enhancement is due to released drugs from the prodrugs, and for Levofloxacin amount of internalization of this drug into the bacteria. A. Original bacterial cell images. B. Intensity plot of those images. 


\section{HPLC method for identifying release of drug and fragments from prodrugs:}

Reverse phase column chromatography has been employed to identify released drug and fragments. Kromasil column RP-18 (250 x $4.6 \mathrm{~mm})$ has been employed in this process, while two types of mobile phase has been used to detect polar fragment-2 (which is often mentioned as [I]), released drug and nonpolar fragment-1(trityl alcohol) released, with due course of reaction progression. For the identification fragment-2 and released drug, gradient based mobile phase has been used (see the table 1 below). When gradient based mobile phase was set for HPLC, then thioester of Levofloxacin eluted at retention time (RT) 5.37min whereas the RT for Levofloxacin and RT for unreacted LSSTR were $8.27 \mathrm{~min}$ and $24.79 \mathrm{~min}$ and we obtained the same retention value for these three fragments in the reaction mixture (Figure S15). But this gradient based mobile phase cannot able to separate low polar trytil alcohol fragment. So to isolate this low-polar trityl alcohol fragment isocratic solvent system, $\mathrm{MeOH}$ : $\mathrm{H}_{2} \mathrm{O}$ : TFA, 90: 10: 0.1 had been employed, ${ }^{3}$ and then trityl alcohol, LSSTr and Levofloxacin were eluted at RT $2.7 \mathrm{~min}, 1.95 \mathrm{~min}$ and $1.32 \mathrm{~min}$ and those values are same for reaction fragments. So in due course of reaction it is obvious that, thiester of Levofloxacin and trityl alcohol is prepared.

Drug is also generated from the thioester intermediate $[\mathrm{I}]$ and it has been clearly understood when HPLC studies were performed with separated intermediate (I) $(5 \mu \mathrm{M})$ at HEPES-buffermethanol; 99:1; v/v; pH 6.5 in absence and presence of GSH. Reaction was monitored by HPLC with half an hour interval time. A reverse phase column chromatography has been employed to measure the kinetics of released drug. Kromasil column RP-18 (250 X 4.6 mm) has been introduced as well as gradient based solvent system has been employed (table3) for this purpose. Under this specified condition, peak for $[\mathbf{I}]$ appeared at retention time of 5.26 min. However, subsequent chromatograms (Figure S16) recorded with increasing time delays revealed that a steady decrease in the $[\mathbf{I}]$ with concomitant increase in peak intensity with 
retention time of $8.07 \mathrm{~min}$. Isolated experiment with pure Levofloxacin under the identical experimental condition revealed that the signal at 8.06 min was solely due to Levofloxacin. This confirmed that with time intermediate was converted to Levofloxacin. Control experiments with externally added GSH $(50 \mu \mathrm{M})$ revealed that GSH failed to alter either the rate of the reaction or the extent of conversion of $\mathbf{I}$ to Levofloxacin. This nullified any possibility of GSH having any role on the conversion shown in step 2 of Scheme 2.

Table S4. Gradient based mobile phase for detection of fragment2 and released drug from LSSTr (prodrug-1):

\begin{tabular}{|l|l|l|l|l|l|}
\hline Time $(\min )$ & $\mathrm{H}_{2} \mathrm{O} \%$ & $\mathrm{MeOH} \%$ & Acetonitrile $\%$ & 0.1 TFA in $\mathrm{H}_{2} \mathrm{O} \%$ & Flow rate \\
\hline 0.0 & 0 & 10 & 10 & 80 & $1 \mathrm{ml} / \mathrm{min}$ \\
\hline 10 & 0 & 20 & 20 & 60 & $1 \mathrm{ml} / \mathrm{min}$ \\
\hline 25 & 0 & 50 & 45 & 5 & $1 \mathrm{ml} / \mathrm{min}$ \\
\hline 30 & 0 & 50 & 45 & 5 & $1 \mathrm{ml} / \mathrm{min}$ \\
\hline 31 & 0 & 10 & 80 & 80 & $1 \mathrm{ml} / \mathrm{min}$ \\
\hline 40 & 0 & 10 & 80 & 80 & $1 \mathrm{ml} / \mathrm{min}$ \\
\hline
\end{tabular}

Table S5. Gradient based mobile phase used for kinetic study.

\begin{tabular}{|l|l|l|l|l|l|}
\hline Time (min) & $\mathrm{H}_{2} \mathrm{O} \%$ & $\mathrm{MeOH} \%$ & Acetonitrile $\%$ & 0.1 TFA in $\mathrm{H}_{2} \mathrm{O} \%$ & Flow rate \\
\hline 0.0 & 0 & 10 & 10 & 80 & $1 \mathrm{ml} / \mathrm{min}$ \\
\hline 10 & 0 & 20 & 20 & 60 & $1 \mathrm{ml} / \mathrm{min}$ \\
\hline 11 & 0 & 10 & 10 & 80 & $1 \mathrm{ml} / \mathrm{min}$ \\
\hline
\end{tabular}




\section{Lipophilicity measurement.}

First n-octanol-saturated water and water-saturated n-octanol were obtained using Millipore water stirred with n-octanol for $24 \mathrm{~h}$ before the two layers were separated by centrifugation (3000 rpm, 5 min). PD1 (LSSTR), PD2 (LSSDMTR) and drug Levofloxacin were dissolved in n-octanol-saturated water. This was then mixed with water-saturated n-octanol in the ratio of 1:1 (v/v). Resulting solvent mixtures were vortexed for $30 \mathrm{~min}$ at room temperature, (two sets has been prepared for each sample) and then were subjected to centrifugation (3000 rpm, $5 \mathrm{~min}$ ) to obtain two distinct separate layers. Samples from each layer were obtained using a fine-gauge needle and the absorbance of respective samples in each phase was determined using UV-vis detector. The concentration in each phase was calculated using reference to calibration absorbance/concentration graphs in each phase and the octanol/water partition coefficient $\left(\log \mathrm{P}\right.$ or $\left.\log \mathrm{K}_{\mathrm{ow}}\right)$ for each respective compounds was then calculated. The value obtained for LSSTr and LSSDMTr is greater than the drug Levofloxacin (shown in the table below). ${ }^{4}$

$$
K o w=\frac{\text { Concentraion in octanol }}{\text { Concentration in water }}
$$$$
\text { Lipophilicity }=\log K_{O W}
$$

Table S6. Table for lipophilicity measurement.

\begin{tabular}{|c|c|c|c|c|}
\hline \multicolumn{5}{|l|}{ A. Levofloxacin } \\
\hline Absorbance in Octanol & $\varepsilon_{\text {oct }}$ & $\mathrm{C}_{\text {oct }}$ & Mean $C_{\text {oct }}$ & $\log K_{\text {ow }}$ \\
\hline 1.66087 & \multirow{2}{*}{16382} & $1.01 \times 10^{-4}$ & \multirow{2}{*}{$1.0035 \times 10^{-4}$} & \multirow{5}{*}{1.31} \\
\hline 1.63408 & & $0.997 \times 10^{-4}$ & & \\
\hline Absorbance in water & $\varepsilon_{\mathrm{w}}$ & $\mathbf{C}_{\mathrm{w}}$ & $C_{w}$ & \\
\hline 0.085 & \multirow[t]{2}{*}{17395} & $4.88 \times 10^{-6}$ & \multirow[t]{2}{*}{$4.97 \times 10^{-5}$} & \\
\hline 0.088 & & $5.0 \times 10^{-6}$ & & \\
\hline \multicolumn{5}{|l|}{ B. Prodrug 1 (LSSTr) } \\
\hline Absorbance in Octanol & Eoct & $\mathrm{C}_{\text {oct }}$ & Mean $C_{\text {oct }}$ & $\log \mathrm{K}_{\mathrm{ow}}$ \\
\hline 1.815 & & $1.207 \times 10^{-4}$ & & \multirow{5}{*}{1.63} \\
\hline 1.8025 & 15035 & $1.198 \times 10^{-4}$ & $1.2025 \times 10^{-4}$ & \\
\hline Absorbance in water & $\varepsilon_{\mathrm{w}}$ & $C_{w}$ & $C_{w}$ & \\
\hline 0.031 & 10438 & $2.96 \times 10^{-6}$ & $2.9 \times 10^{-6}$ & \\
\hline 0.0297 & & $2.84 \times 10^{-6}$ & & \\
\hline \multicolumn{5}{|c|}{ C. Prodrug 2 (LSSDMTr) } \\
\hline Absorbance in Octanol & $\varepsilon_{\text {oct }}$ & $\mathrm{C}_{\text {oct }}$ & Mean $C_{\text {oct }}$ & $\log \mathrm{K}_{\mathrm{ow}}$ \\
\hline 1.503 & & $1.22 \times 10^{-4}$ & & \\
\hline 1.514 & 12315 & $1.22 \times 10^{-4}$ & $1.22 \times 10^{-4}$ & \multirow{4}{*}{1.67} \\
\hline Absorbance in water & $\varepsilon_{\mathrm{w}}$ & $\mathrm{C}_{\mathrm{w}}$ & $\mathbf{C}_{\mathrm{w}}$ & \\
\hline 0.028 & 10734 & $2.6 \times 10^{-6}$ & $2.67 \times 10^{-6}$ & \\
\hline 0.0295 & & $2.74 \times 10^{-6}$ & & \\
\hline
\end{tabular}




\section{Quantum yield measurement.}

Reference quantum yield of prodrug1 and prodrug2 have been measured with respect to the drug Levofloxacin. ${ }^{5}$ According to the below mentioned formula and the measurements have been done $1 \%$ DMSO water medium. From this experiment obtained quantum yields are .0051 , 0.00495 and 0.01 respectively for prodrug1, prodrug2 and ethylester of Levofloxacin according to the below mentioned equation. ${ }^{6,7}$

$$
\phi_{\mathrm{u}}=\phi_{\mathrm{s}} \frac{A_{s}}{A_{u}} \frac{F_{u}}{F_{s}} \frac{\eta_{u}^{2}}{\eta_{s}^{2}}
$$

where $\phi_{\mathrm{s}}$ is the fluorescence quantum yield of the standard, $A$ is the absorbance at the excitation wavelength, $F$ is the area of the emission spectrum and $\eta$ is the refractive index of the medium. The $s$ and $u$ subscripts refer to the standard and unknown parameters respectively. 


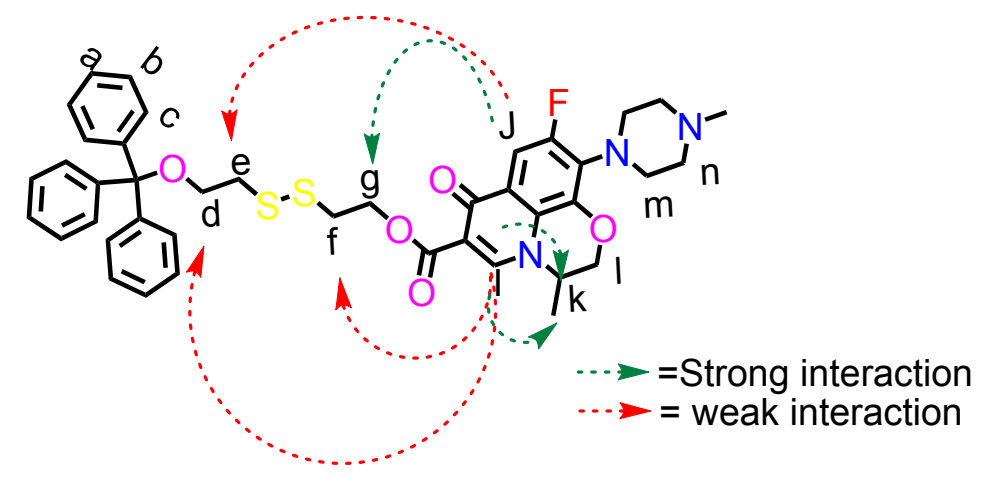

ROESY correlation (accounting other 2D NMRs). In LSSTr 4-CH2 protons (recorded in Bruker $500 \mathrm{MHz}$, In DMSOd 6$)$ of ethelene moiety are appeared at $\delta 4.37,3.25\left(\mathrm{O}-\mathrm{CH}_{2}\right)$ and 2.97, $2.95\left(\mathrm{~S}-\mathrm{CH}_{2}\right)\left(\mathrm{HSQC}\right.$ spectrum of LSSTR where DEPT- ${ }^{1} \mathrm{H}$ NMR correlation has been done). A proton-proton correlation has been found between $2.97 / 4.37$ and 2.95/3.25 proton pairs in COSY spectrum. From this analysis proton peaks $\delta 4.37,3.25,2.97,2.95$ can be assigned as $\mathrm{H}_{\mathrm{g}}, \mathrm{H}_{\mathrm{d}}, \mathrm{H}_{\mathrm{f}}$ and $\mathrm{H}_{\mathrm{e}}$ as shown above. It is revealed from ROESY NMR that Levofloxacin proton $\mathrm{H}_{\mathrm{I}}$ has very weak interaction with $2.97\left(\mathrm{H}_{\mathrm{f}}\right), 4.37\left(\mathrm{H}_{\mathrm{g}}\right)$, strong interaction with $\mathrm{H}_{\mathrm{k}}$ and methyl protons of that $\mathrm{H}_{\mathrm{k}}$ attached carbon. While $\mathrm{H}_{\mathrm{J}}$ has moderate or strong interaction with $2.95\left(\mathrm{H}_{\mathrm{e}}\right)$ and $3.25\left(\mathrm{H}_{\mathrm{d}}\right)$. These $\mathrm{H}_{\mathrm{d}}$ and $\mathrm{H}_{\mathrm{e}}$ has also strong interaction with trityl aromatic protons. 


\section{Graph of MTT Assay:}

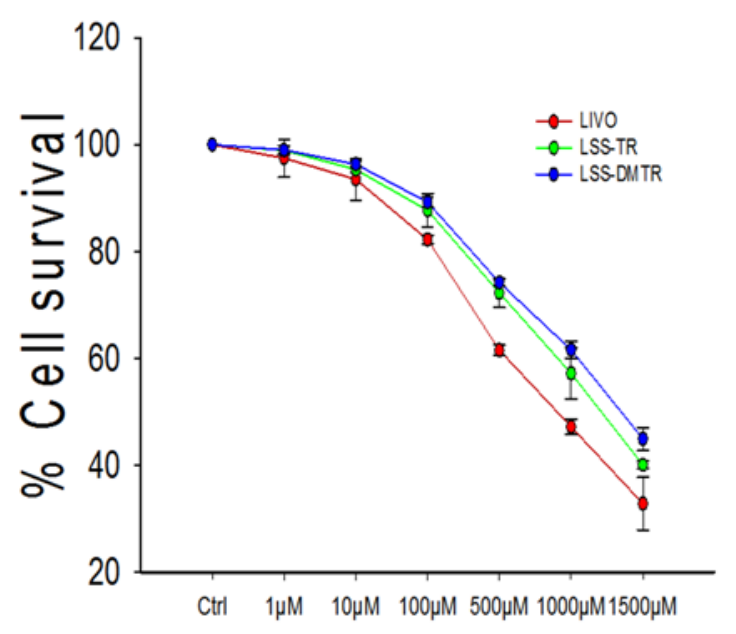

Figure S3. Plot of MTT assay of Levofloxacin, LSSTr and LSSDMTr. 
Deconvolution spectra of L, LSSTr (PD1) and LSSDMTr (PD1):

A.

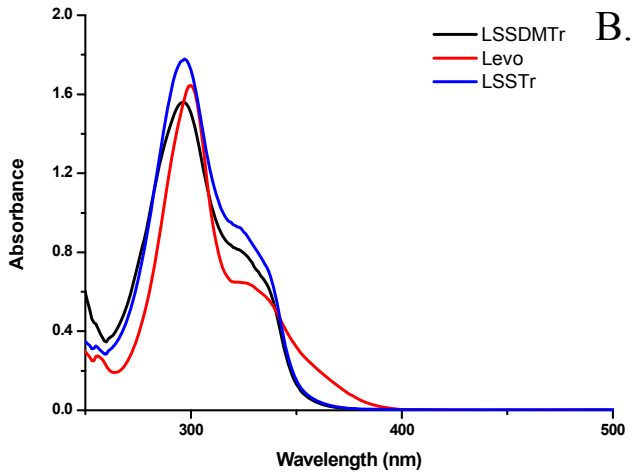

C.

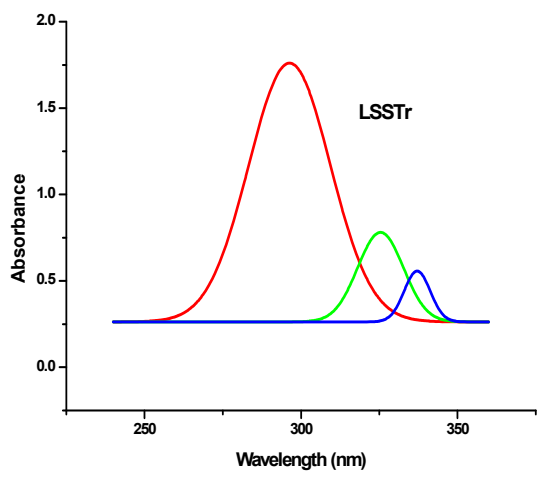

B.

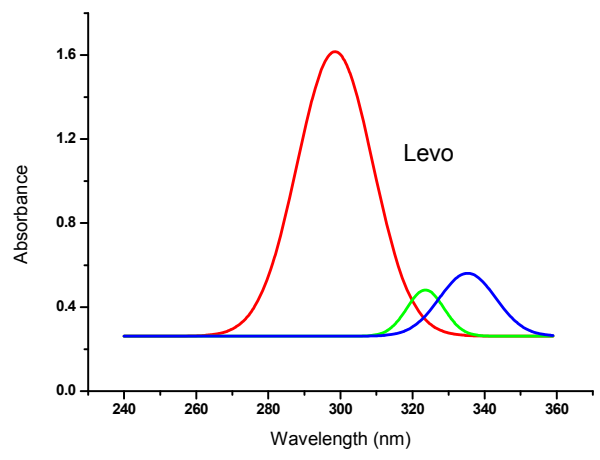

D.

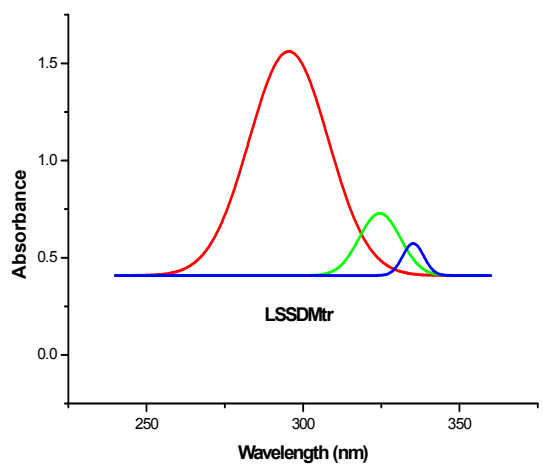

Figure S4. A. Absorption spectra of Levofloxacin, LSStr and LSSDMTr in THF. Deconvolution of absorption spectra of B. Levofloxacin, C. LSSTr and D. LSSDMTr in THF solvent. 
Spectral Characterization of trityl-SS-OH:
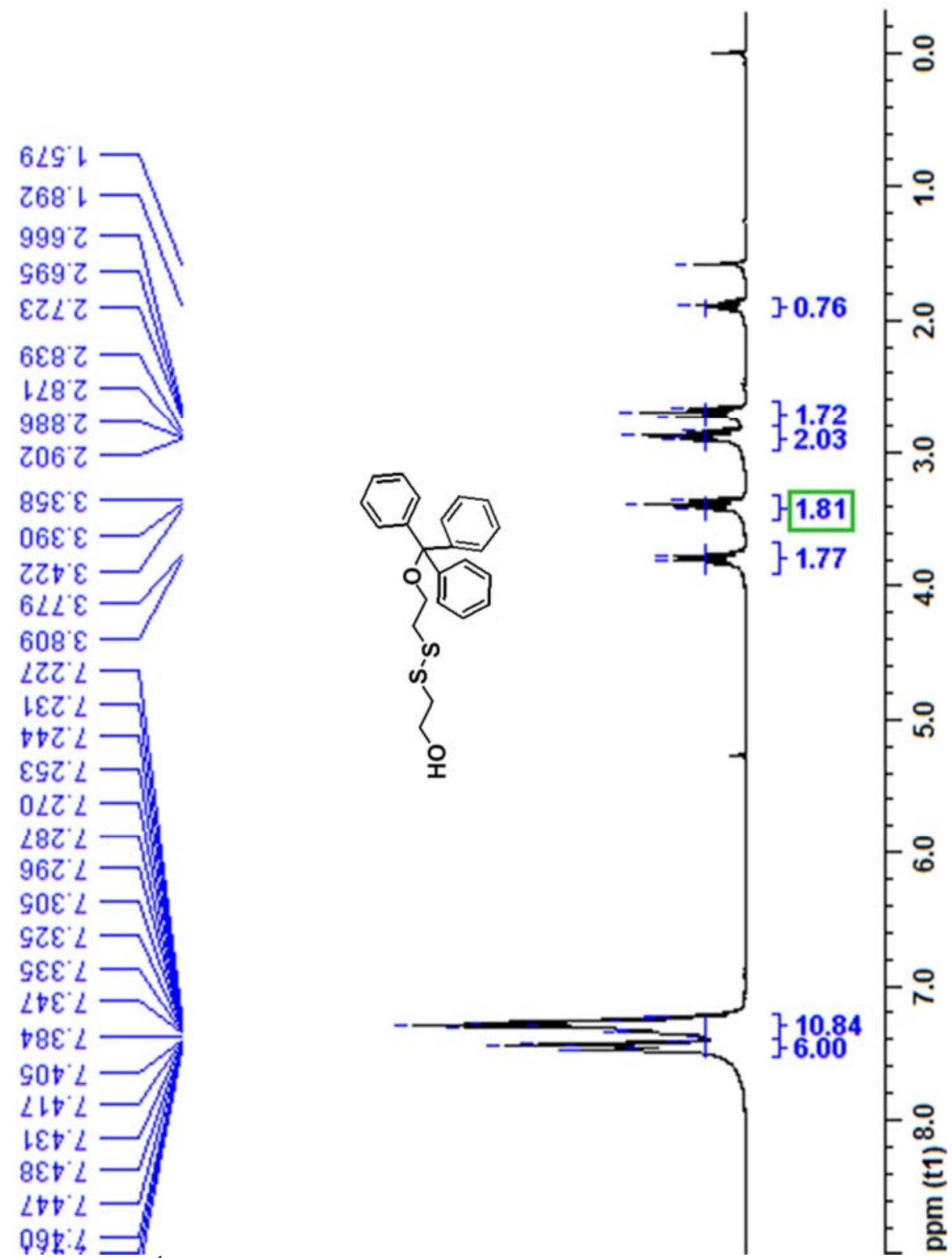

Figure S5. ${ }^{1} \mathrm{H}$ NMR of trityl-SS-OH in $\mathrm{CDCl}_{3}$ 


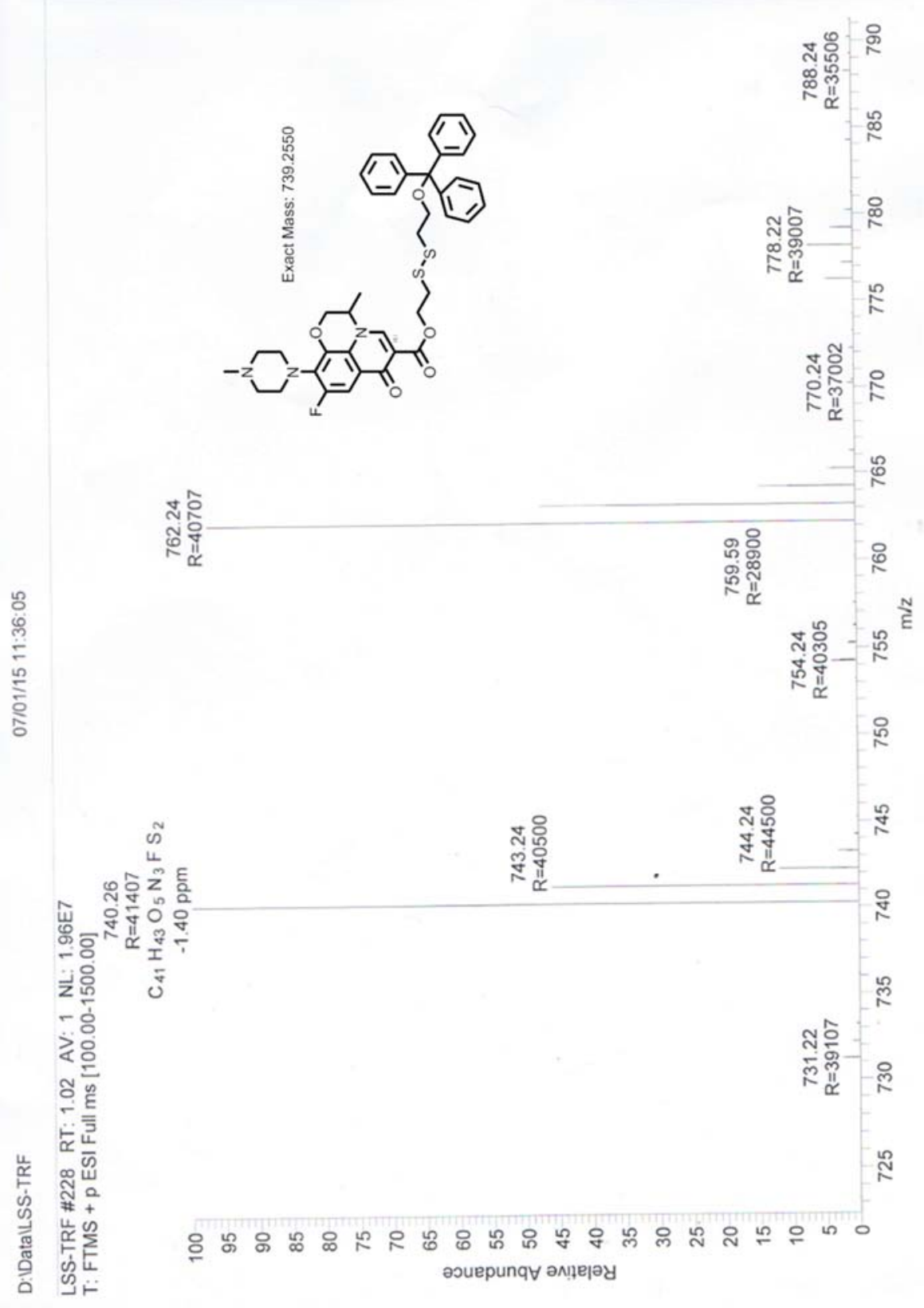

Figure S6. HRMS spectrum of PD 1 (LSSTr). 


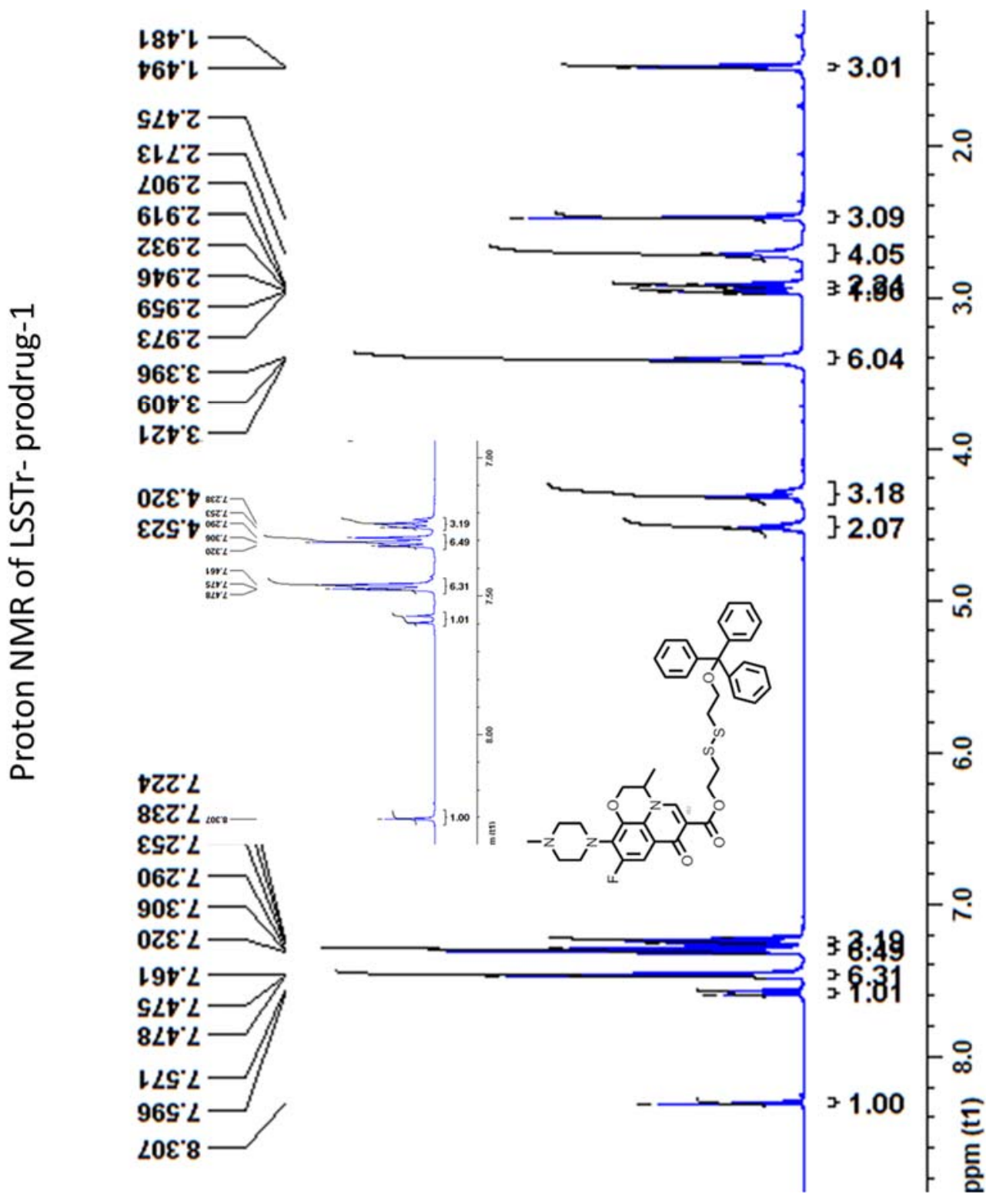

Figure S7. ${ }^{1} \mathrm{H}$ NMR of PD 1 (LSSTr) in $\mathrm{CDCl}_{3}$. 


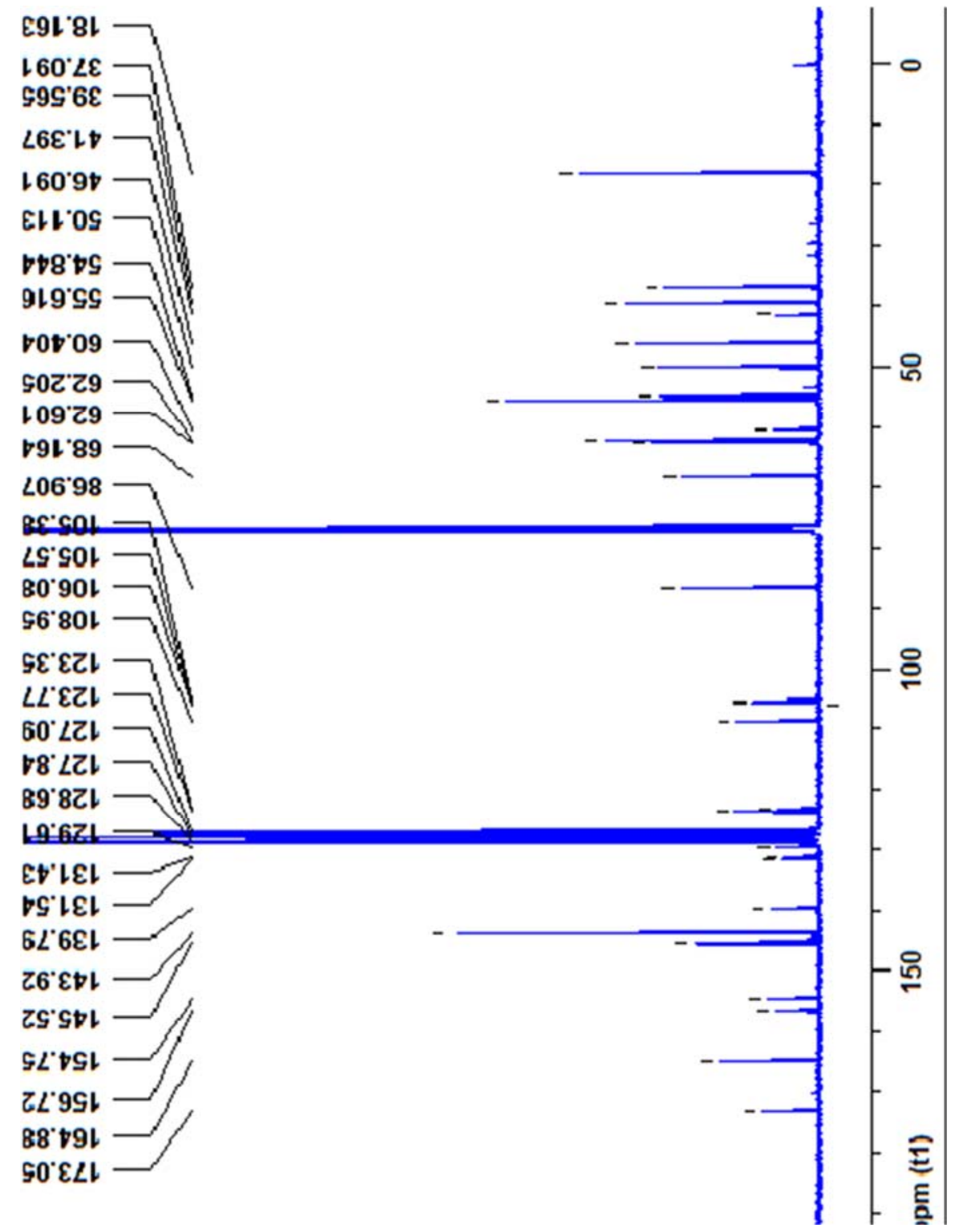

Figure S8. ${ }^{13} \mathrm{C}$ NMR of PD1 in $\mathrm{CDCl}_{3}$. 


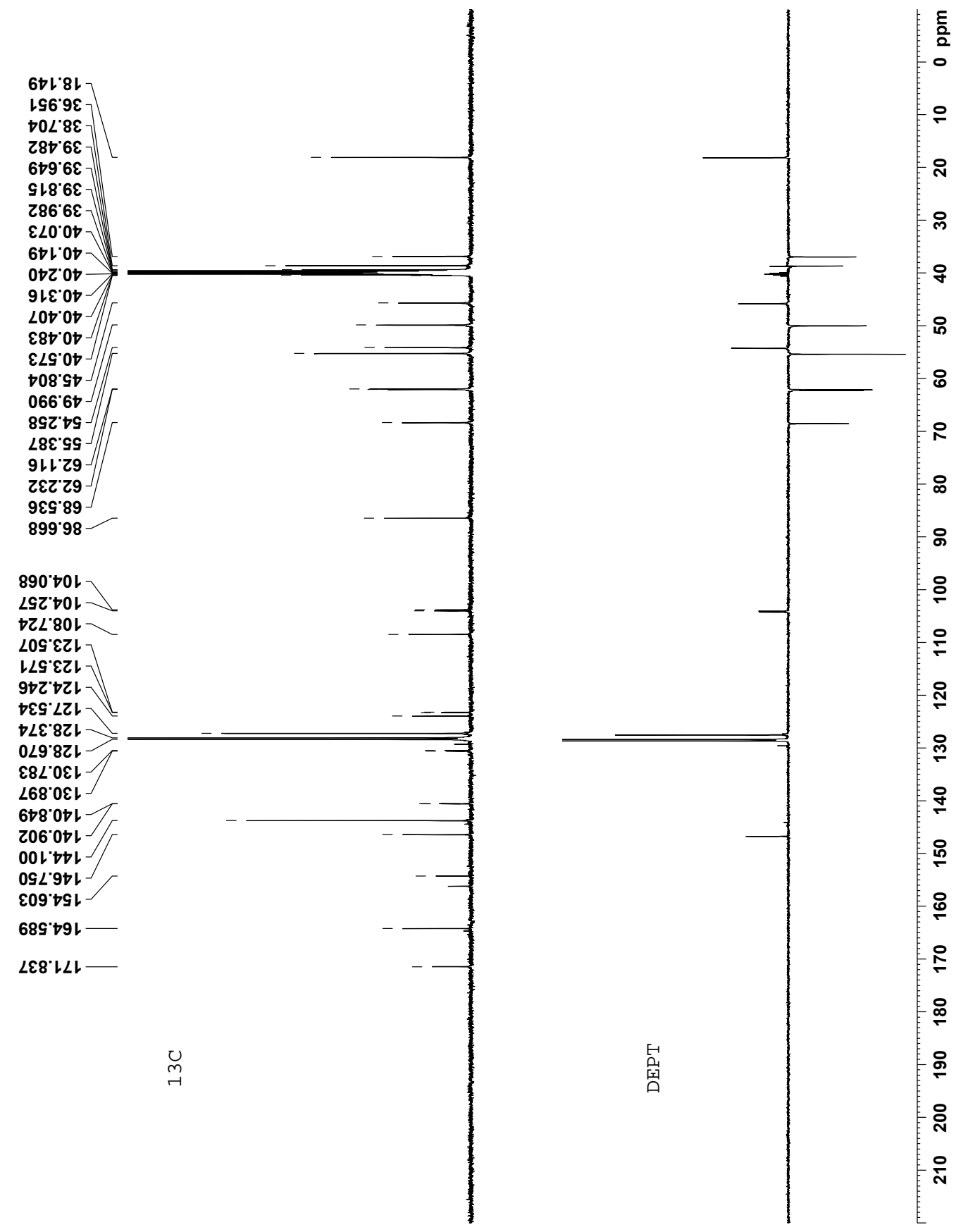

Figure S9. ${ }^{13} \mathrm{C}$ and DEPT NMR of PD1 in DMSO $d_{6}$ solution. 


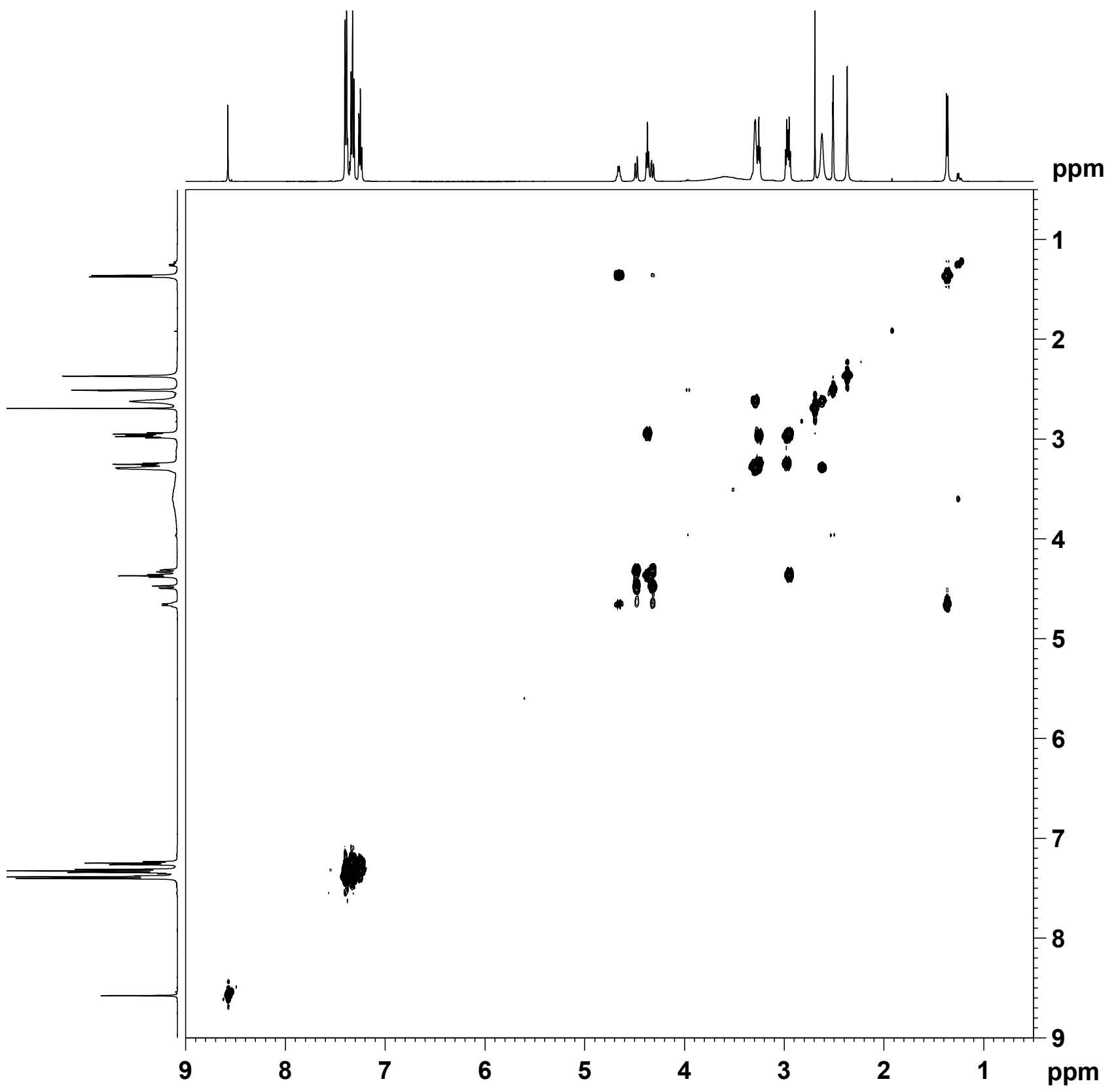

Figure S10. COSY spectrum of PD 1 in DMSO-d ${ }_{6}$ medium. 

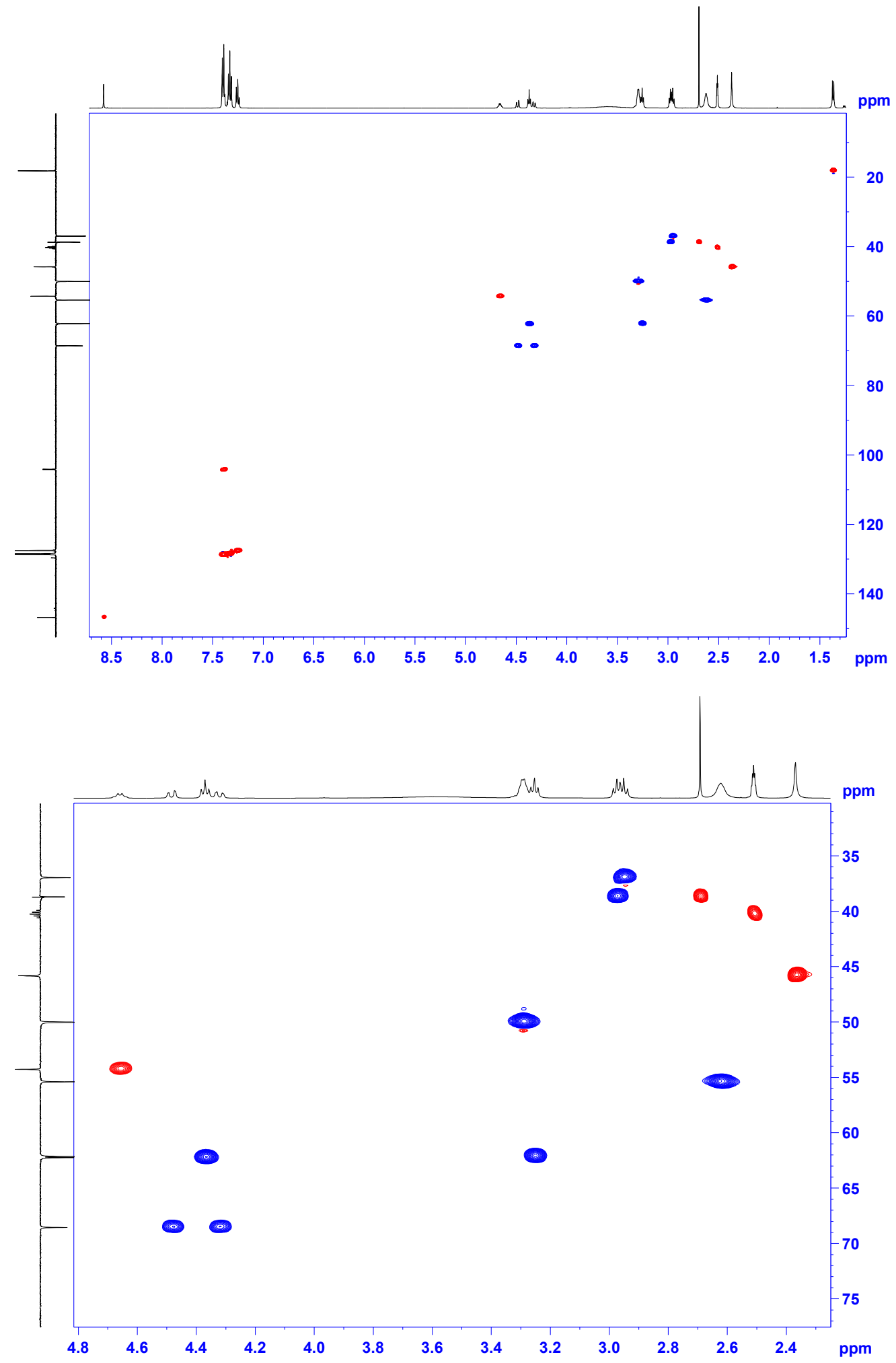

Figure S11. HSQC of PD1 in DMSO-d $\mathrm{d}_{6}$ medium. 

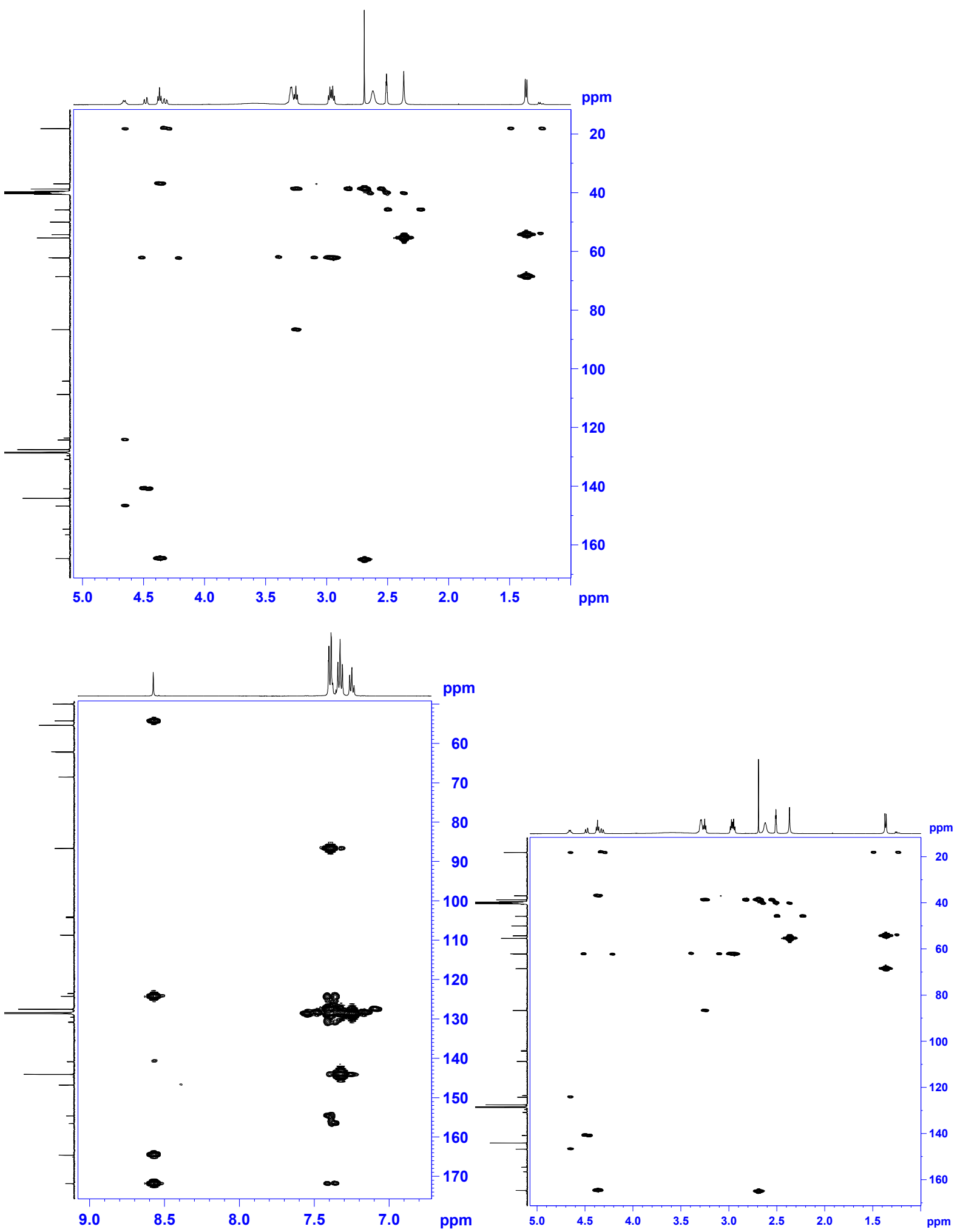

Figure S12. HMBC of PD1 in DMSO-d $\mathrm{d}_{6}$ medium. 

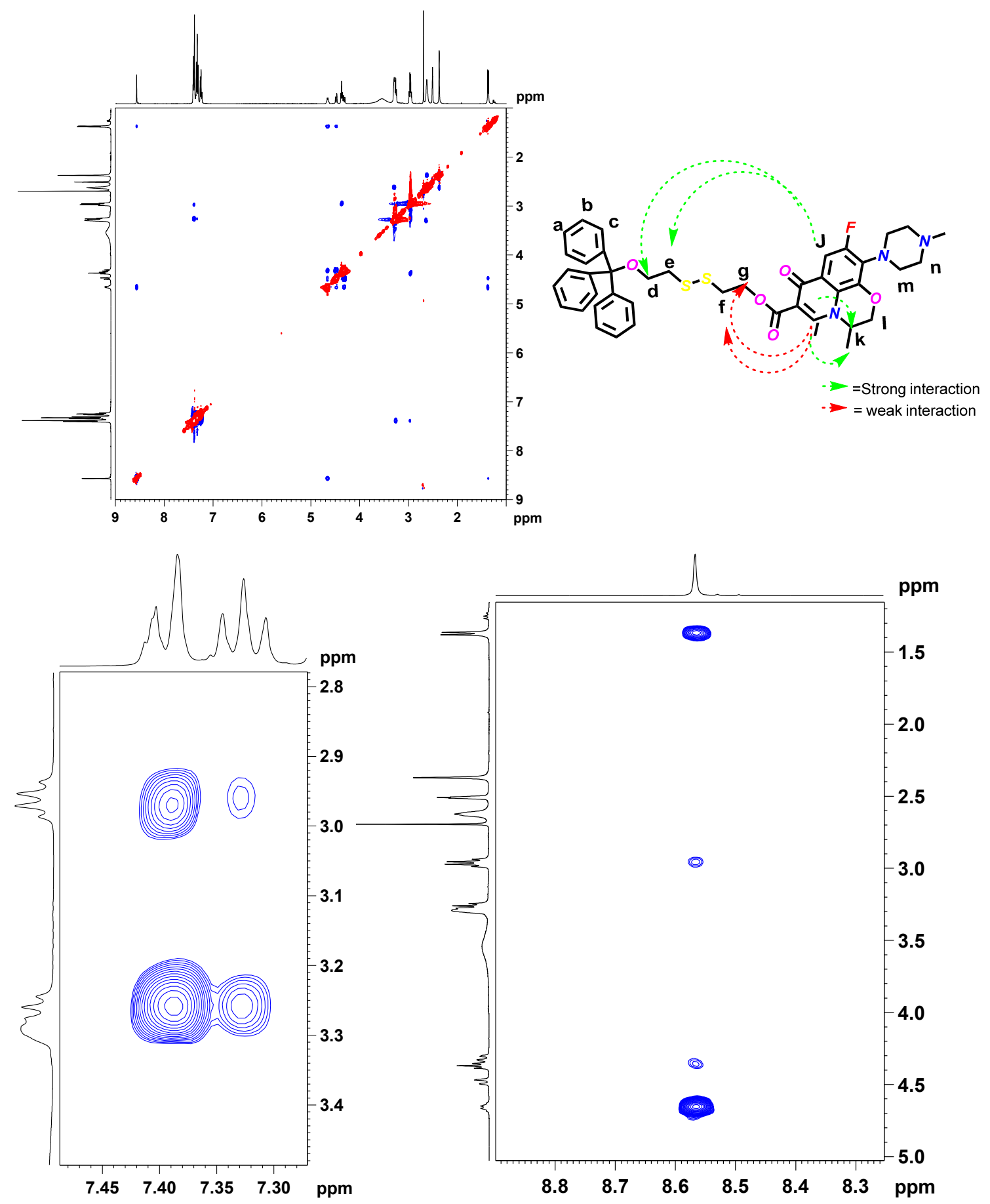

Figure S13. ROESY spectra of PD1 in DMSO-d $\mathrm{d}_{6}$ medium. 
Spectral Characterization of PD2 (LSSDMTr):

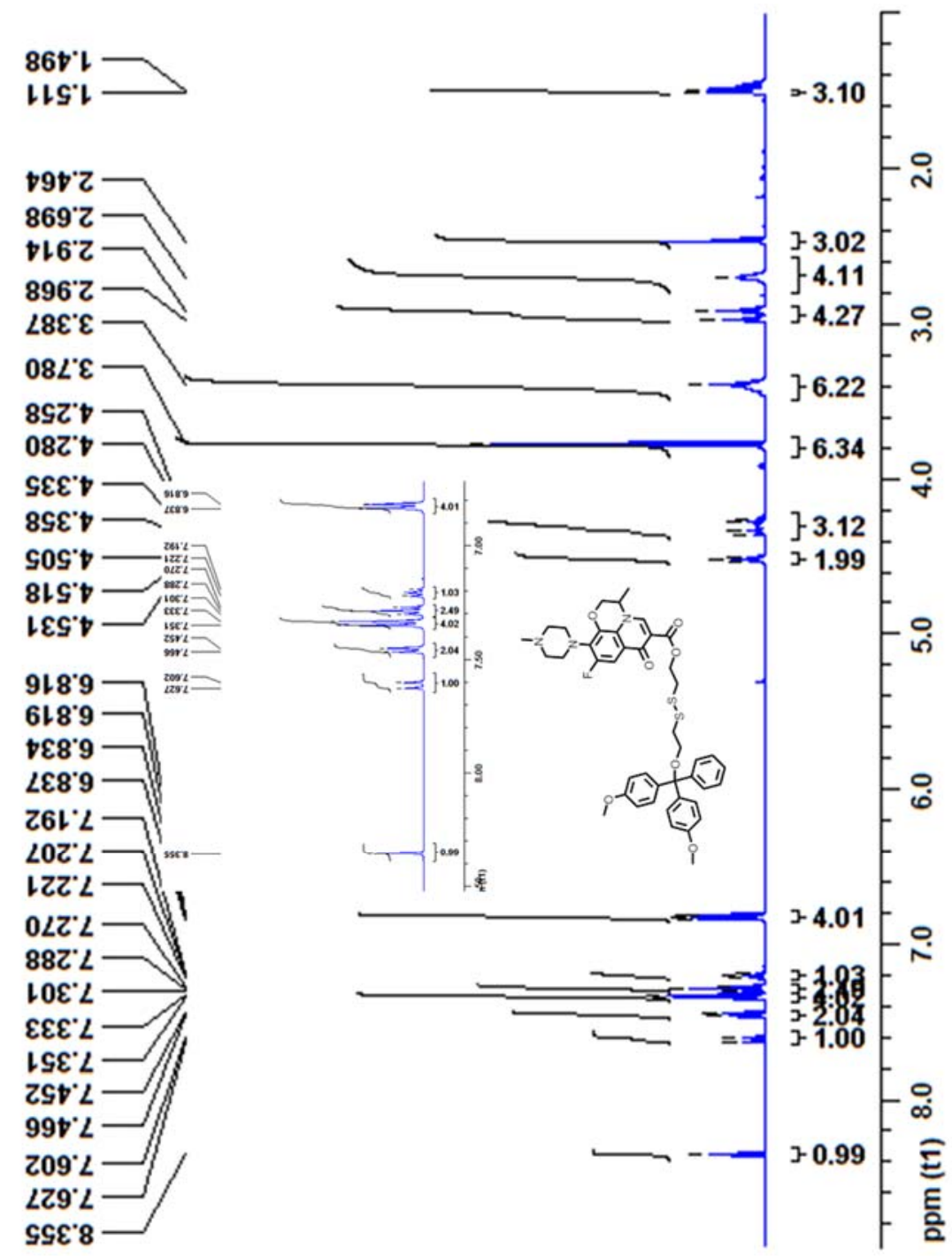

Figure S14. ${ }^{1} \mathrm{H}$ NMR of PD2 (LSSDMTr) in $\mathrm{CDCl}_{3}$. 


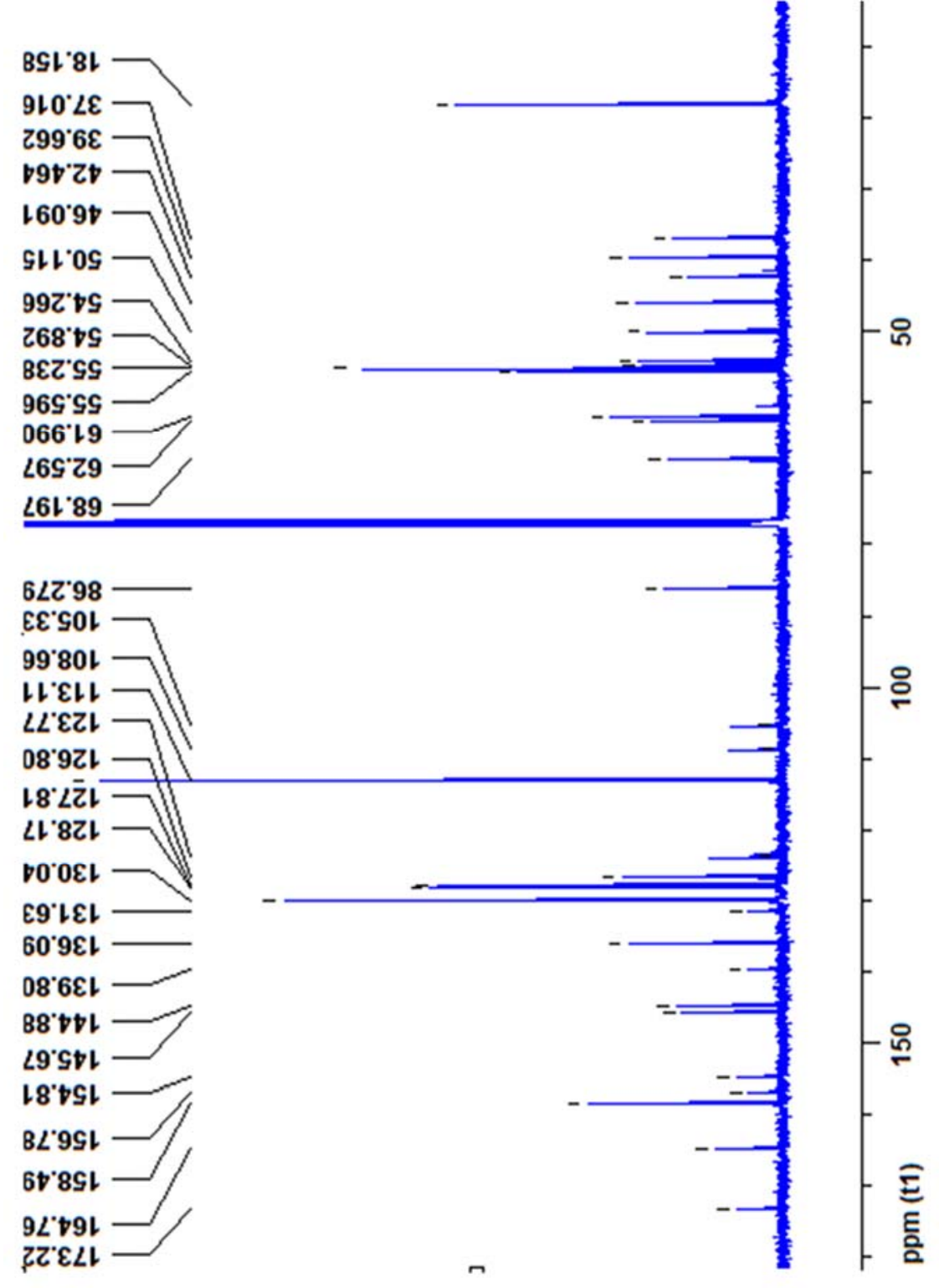

Figure S15. ${ }^{13} \mathrm{C}$ NMR of PD2 in $\mathrm{CDCl}_{3}$. 


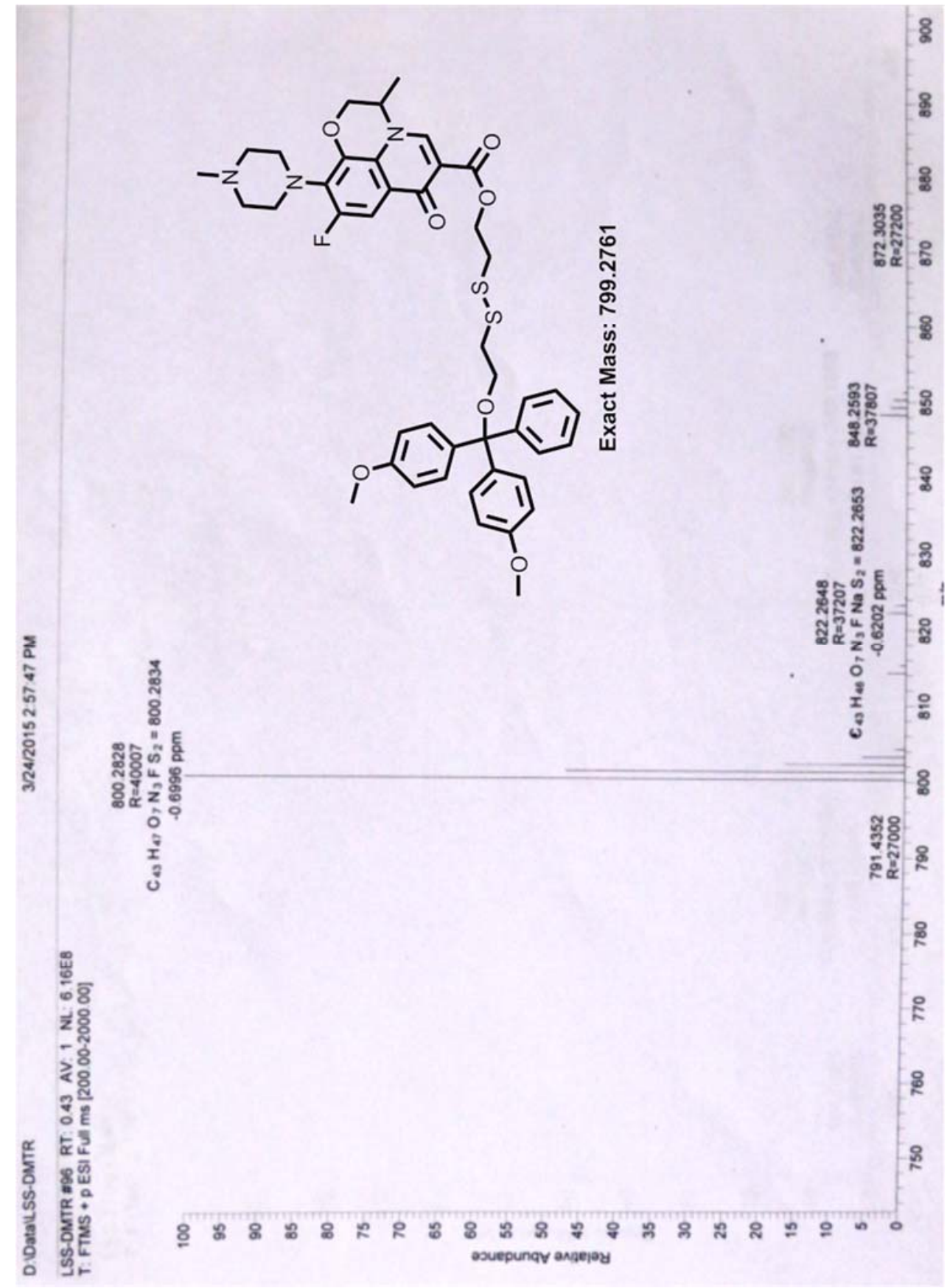

Figure S16. HRMS spectrum of PD2. 
1. a.

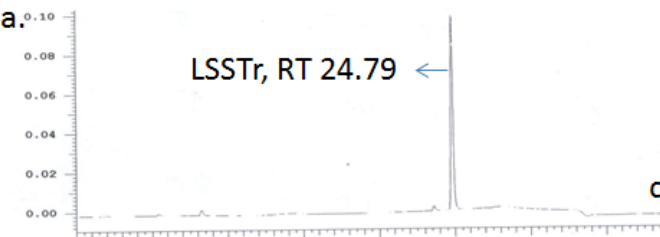

b.

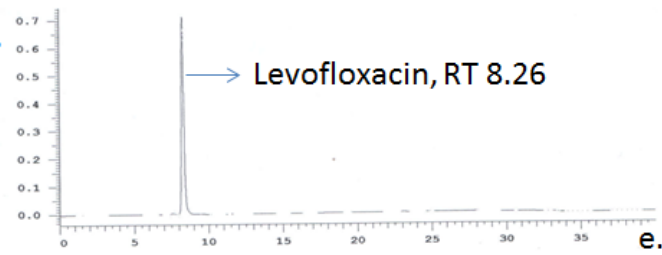

$\longrightarrow$ Fragment-2 RM-1h
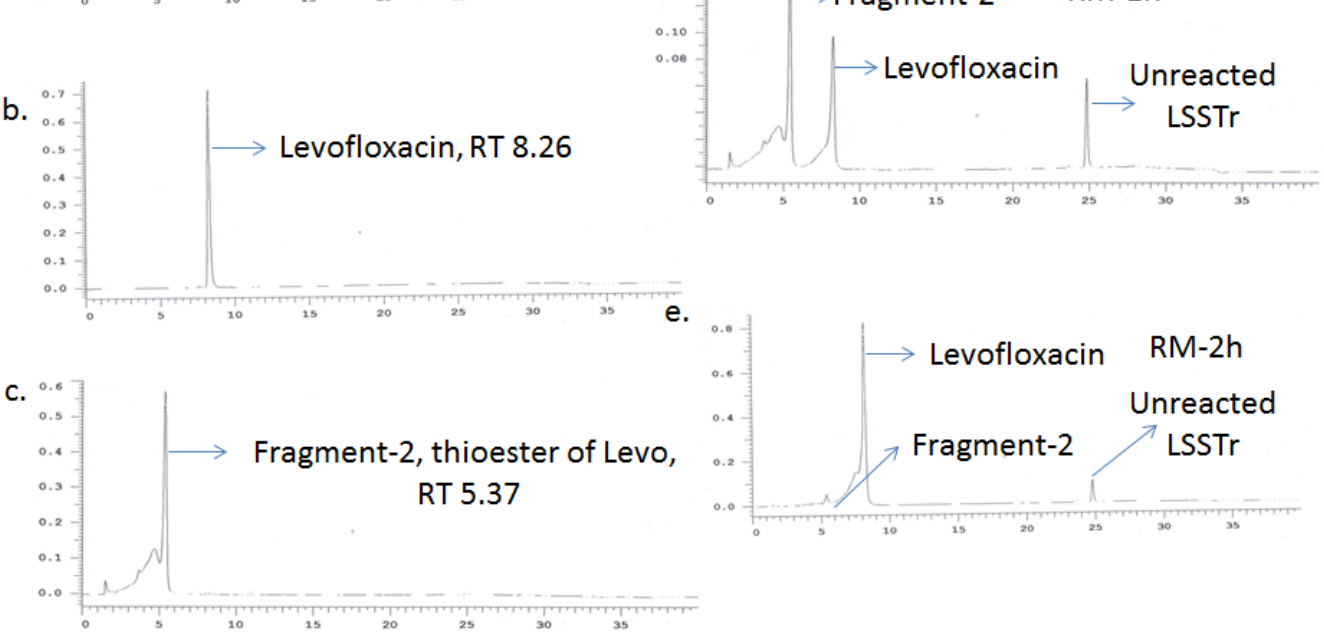

2.

a.
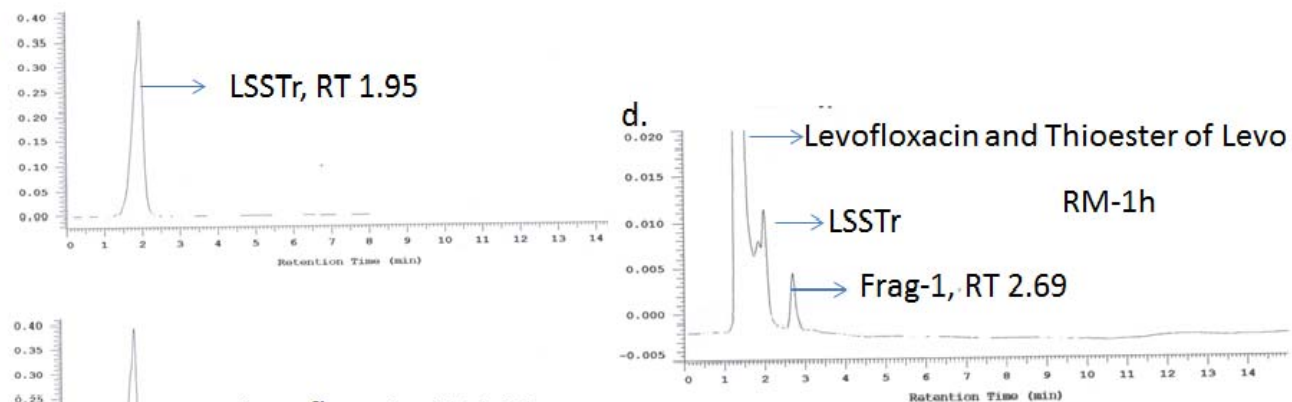

b.

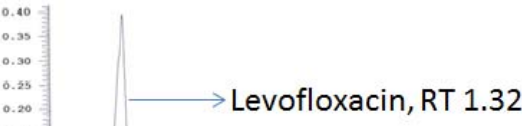

e.

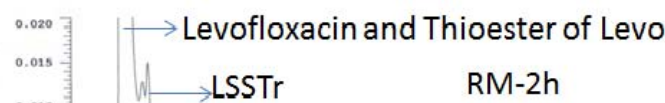

c.

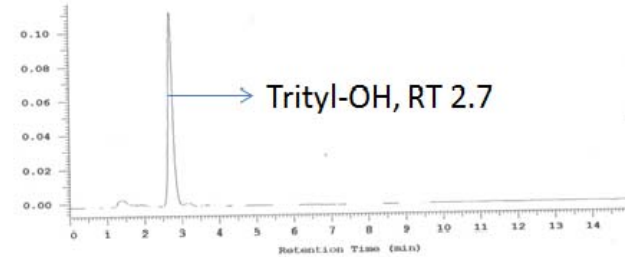

Frag-1, RT 2.69

Figure S17. HPLC Chromatogram using Kromasil column RP-18 (250 X $4.6 \mathrm{~mm})$ for identification of fragment-1, fragment-2 and released drug in the reaction mixture. 1. Gradient based solvent system has been employed to identify Fragment 2, released drug and LSSTr while monitoring wave length was 290 nm (a. LSSTR, b. Levofloxacin, c. Fragment 2 d. RM after one hour and e.RM after 2 h), 2. Isocratic solvent system has been employed to determine fragment-1 in the reaction mixture where monitoring wavelength was $254 \mathrm{~nm}$ (a. LSSTr, b. Levofloxacin, c.Trityl-OH, d. RM after $1 \mathrm{~h}$ and e.RM after $2 \mathrm{~h}$ ). 


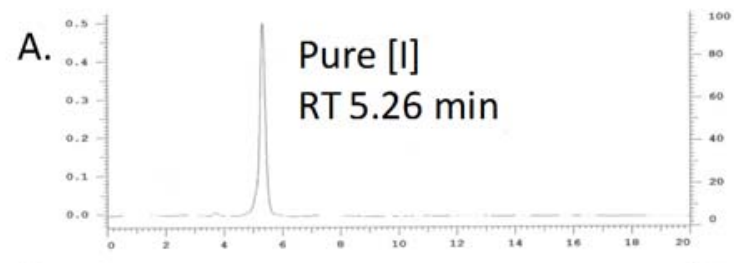

B.

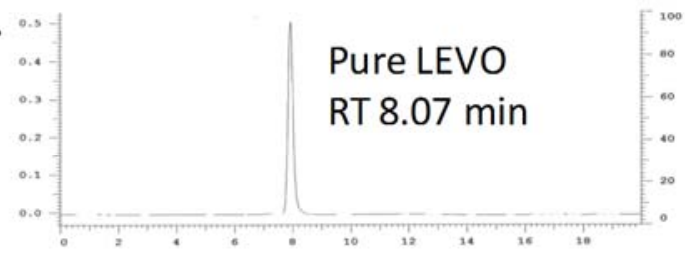

C.

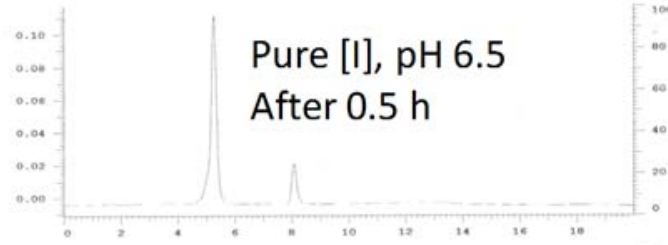

D.

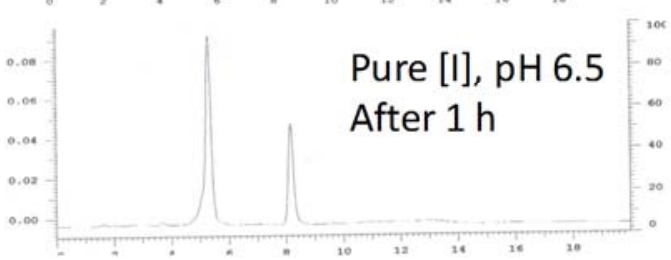

E.

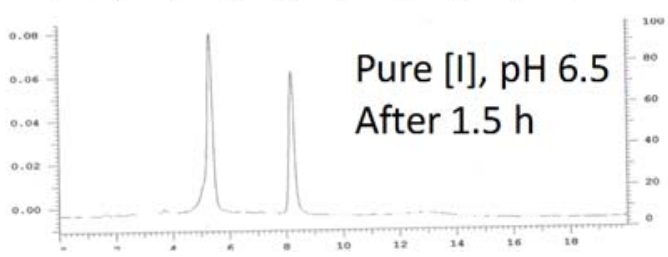

F.

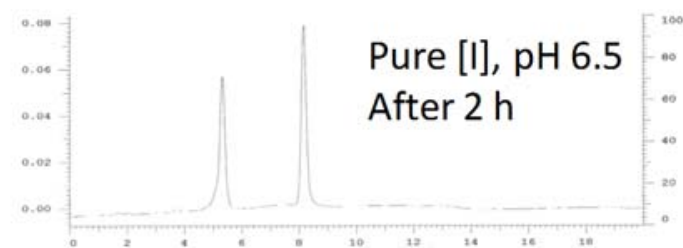

G.

H.

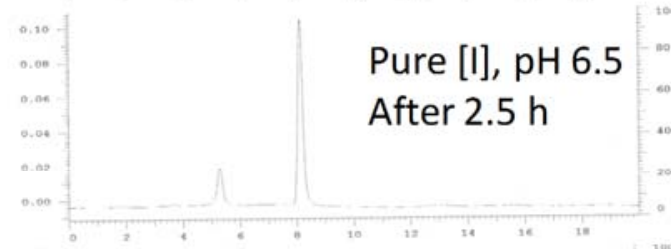

I.

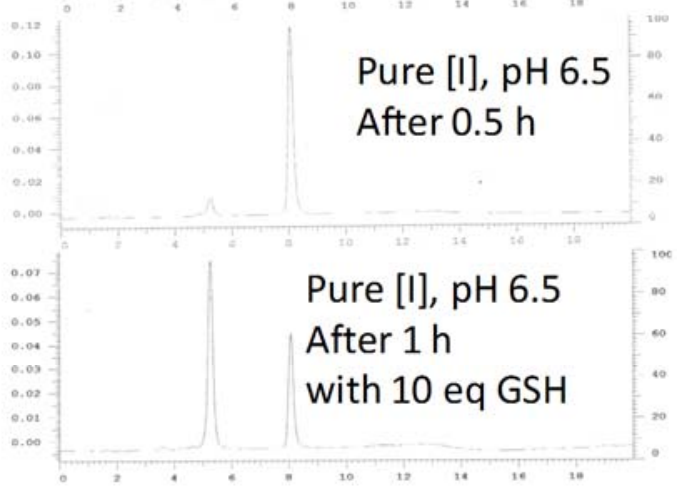

J.

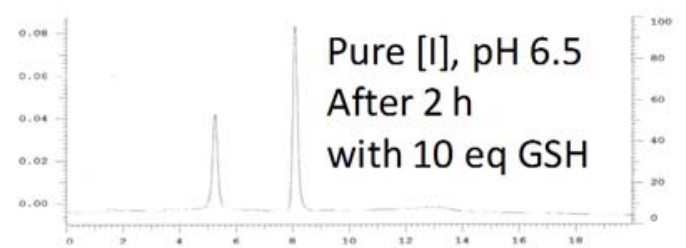

Figure S18. Kinetic study from HPLC. A.B. pure form of INT-1 and Levofloxacin drug, B-H HPLC chromatograms of formation of Levofloxacin drug from the intermediate-1, with 0.5 hour interval. I.J. HPLC chromatogram of formation of levofloxacin drug (after one and two hour) with addition of GSH 10 equivalent. 


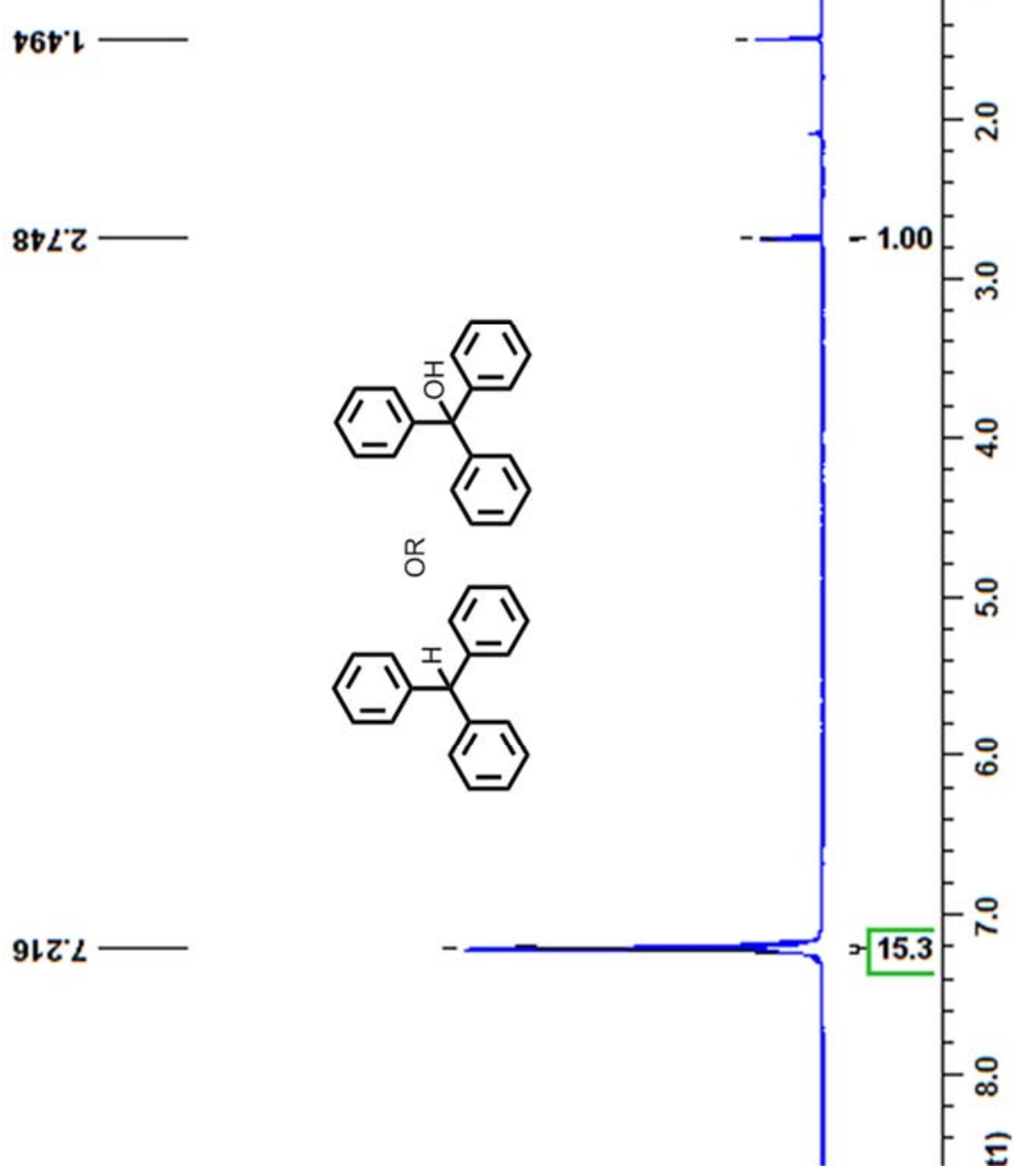

Figure S19. ${ }^{1} \mathrm{H}$ NMR of hydroxyl trityl fragment in $\mathrm{CDCl}_{3}$. 


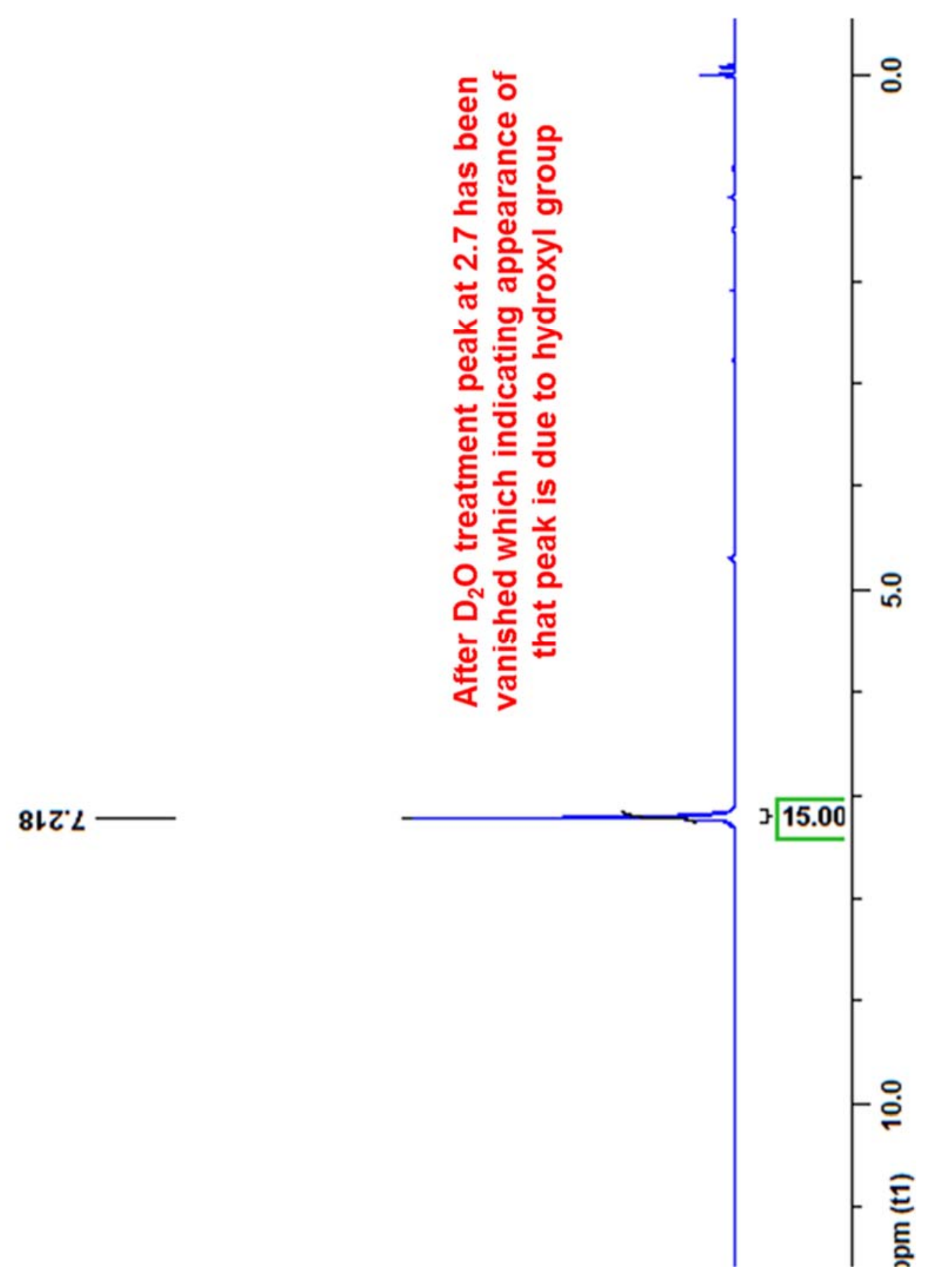

Figure S20. ${ }^{1} \mathrm{H}$ NMR of Hydroxyl trityl compound after treatment with $\mathrm{D}_{2} \mathrm{O}$. 


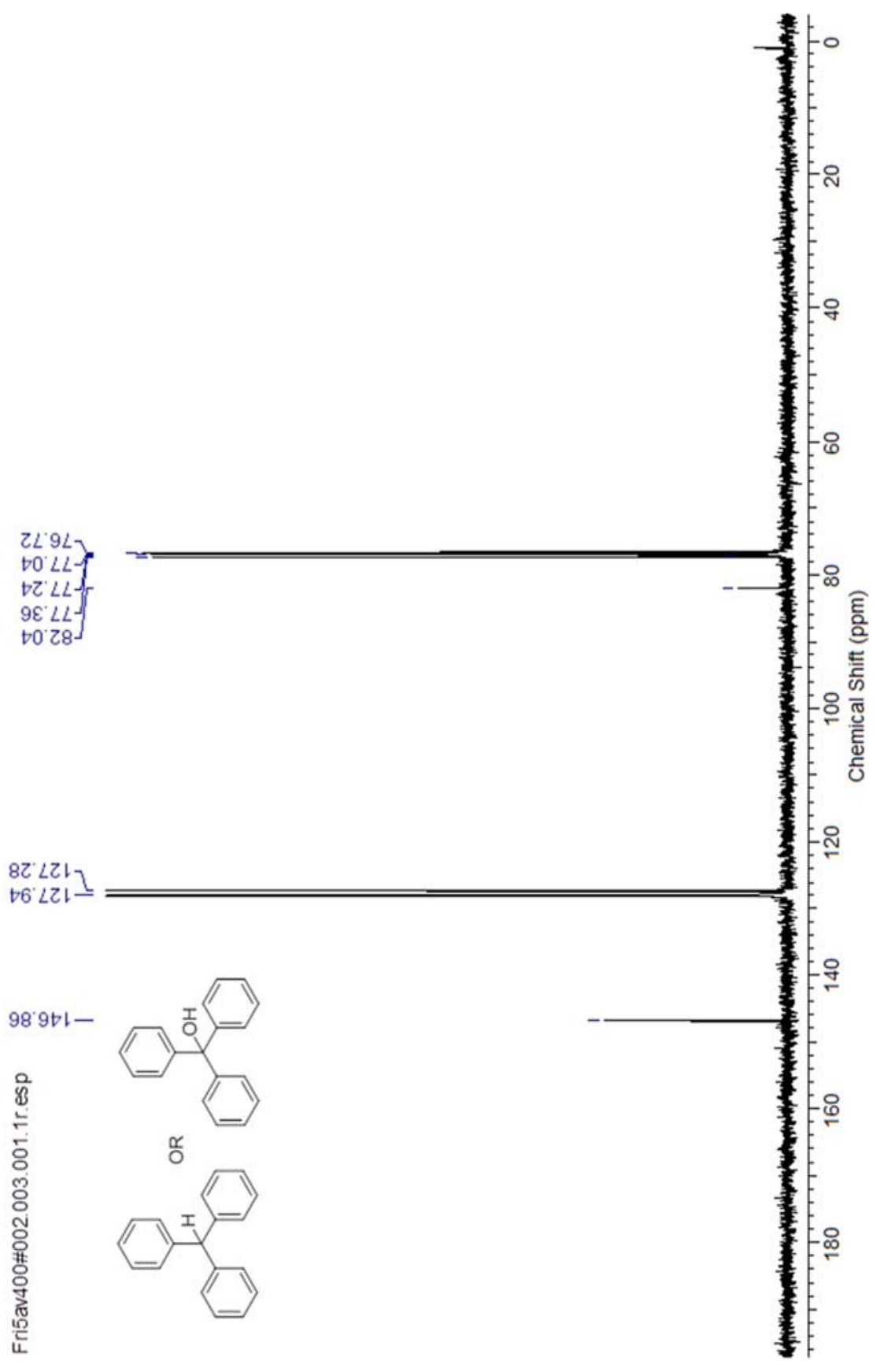

Figure S21. ${ }^{13} \mathrm{C}$ NMR of Hydroxyl trityl compound in $\mathrm{CDCl}_{3}$. 


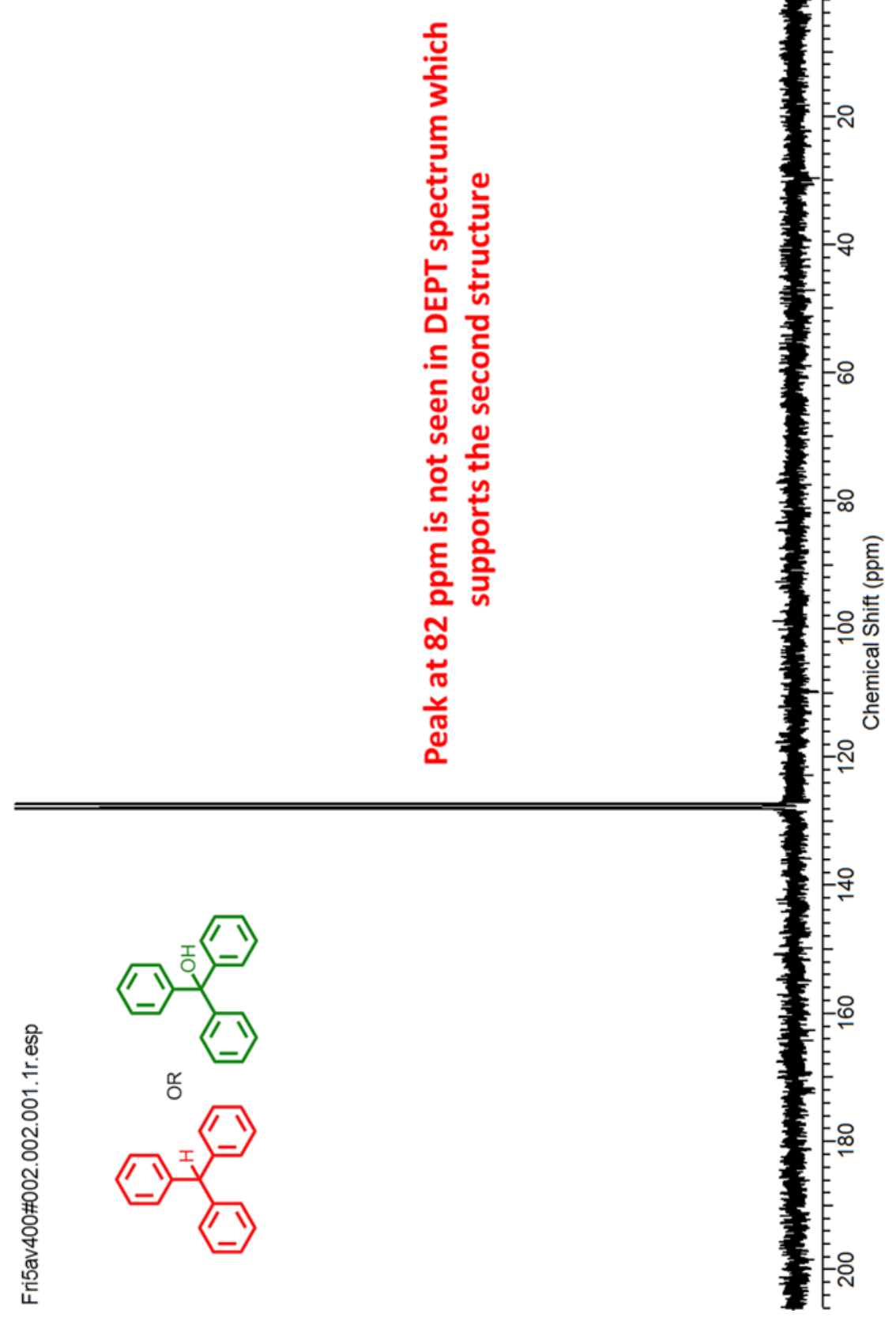

Figure S22. DEPT NMR of Hydroxyl trityl compound in $\mathrm{CDCl}_{3}$. 


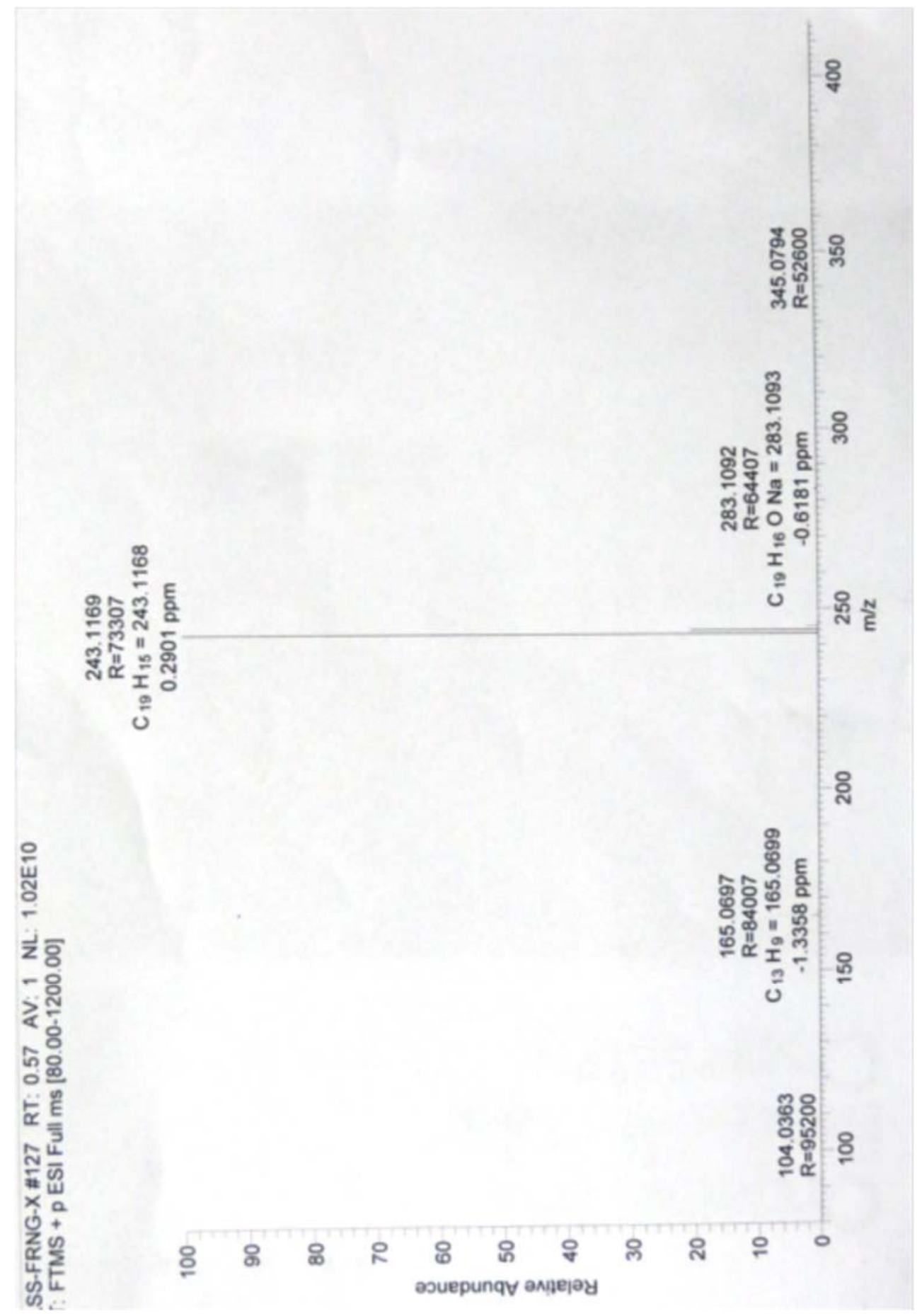

Figure. S23. HRMS spectrum of Hydroxyl trityl compound. 


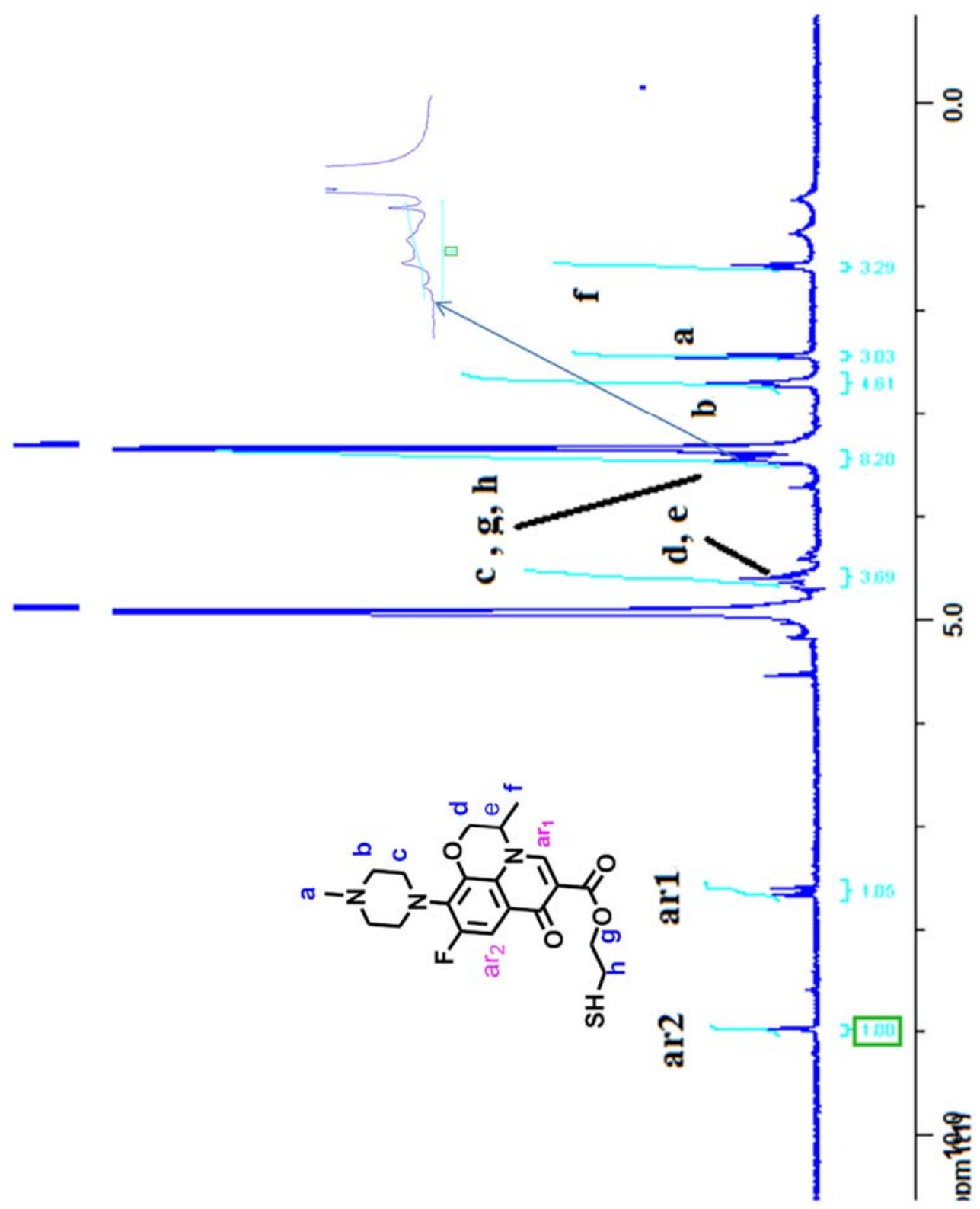

Figure. S24. ${ }^{1} \mathrm{H}$ NMR thiolester of Levofloxacin, intermediate $\mathbf{I}$ in $\mathrm{CD}_{3} \mathrm{OD}$. 


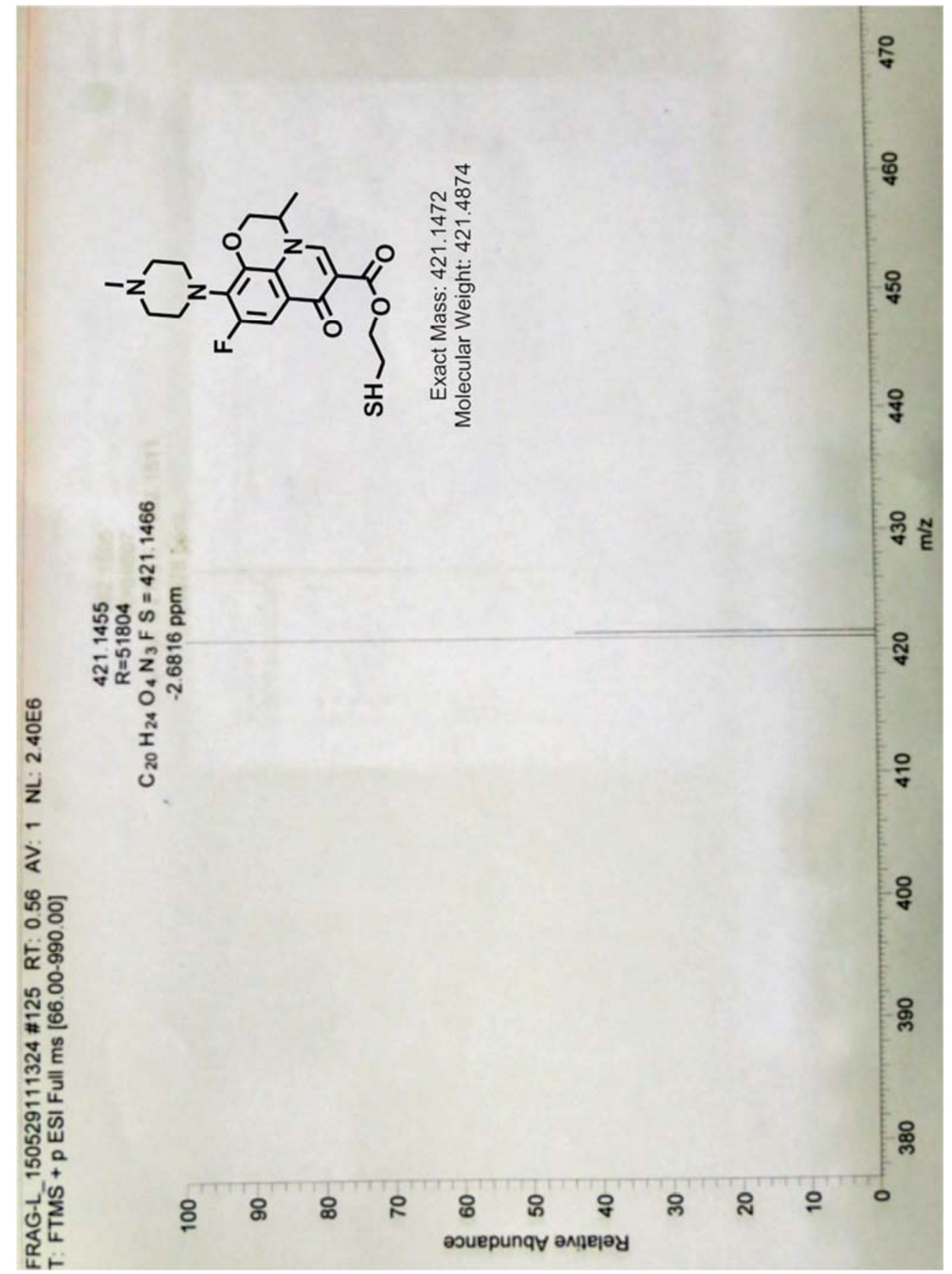

Figure S25. HRMS spectrum of intermediate I. 


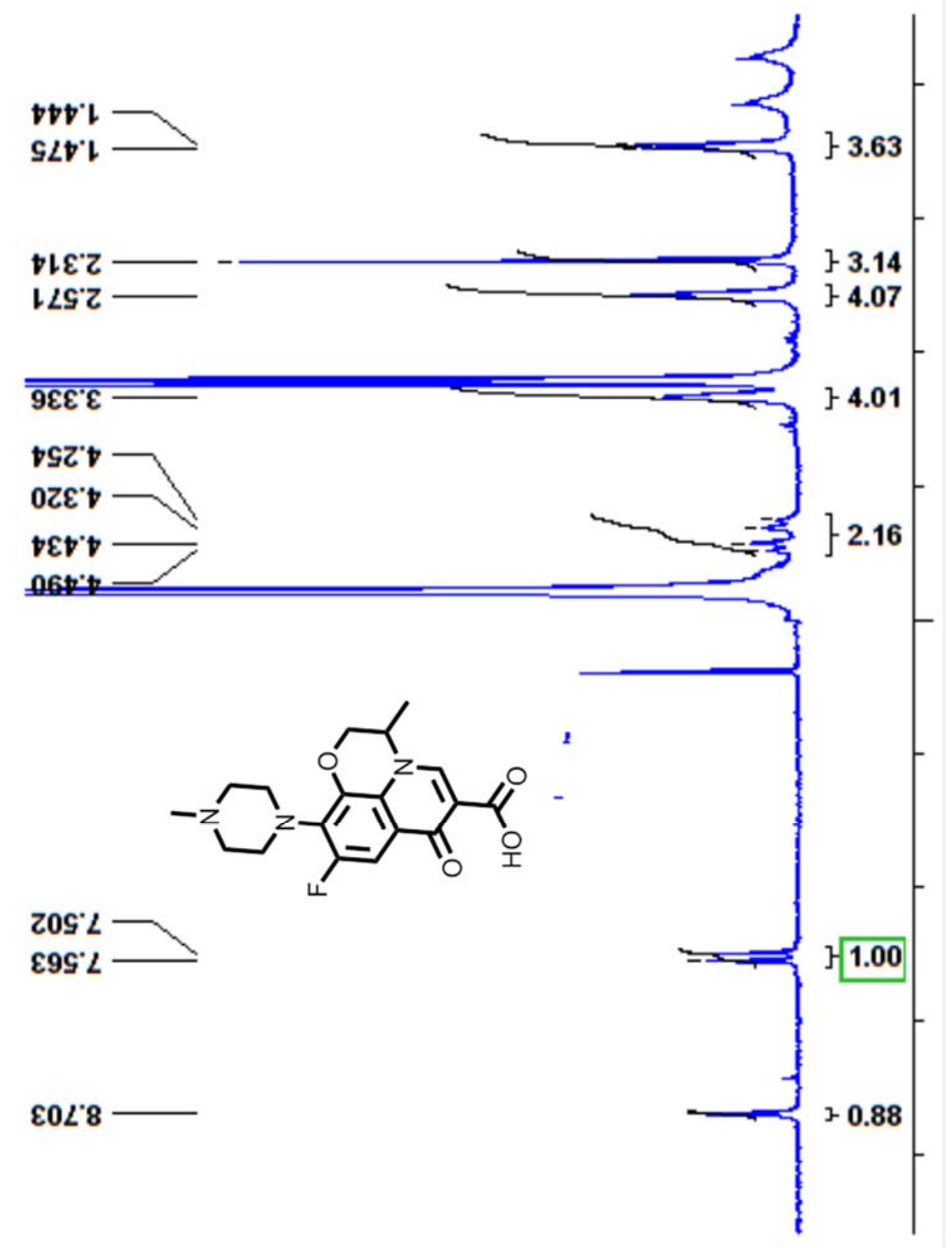

Figure S26. ${ }^{1} \mathrm{H}$ NMR of fragment Levofloxacin in $\mathrm{CD}_{3} \mathrm{OD}$. 


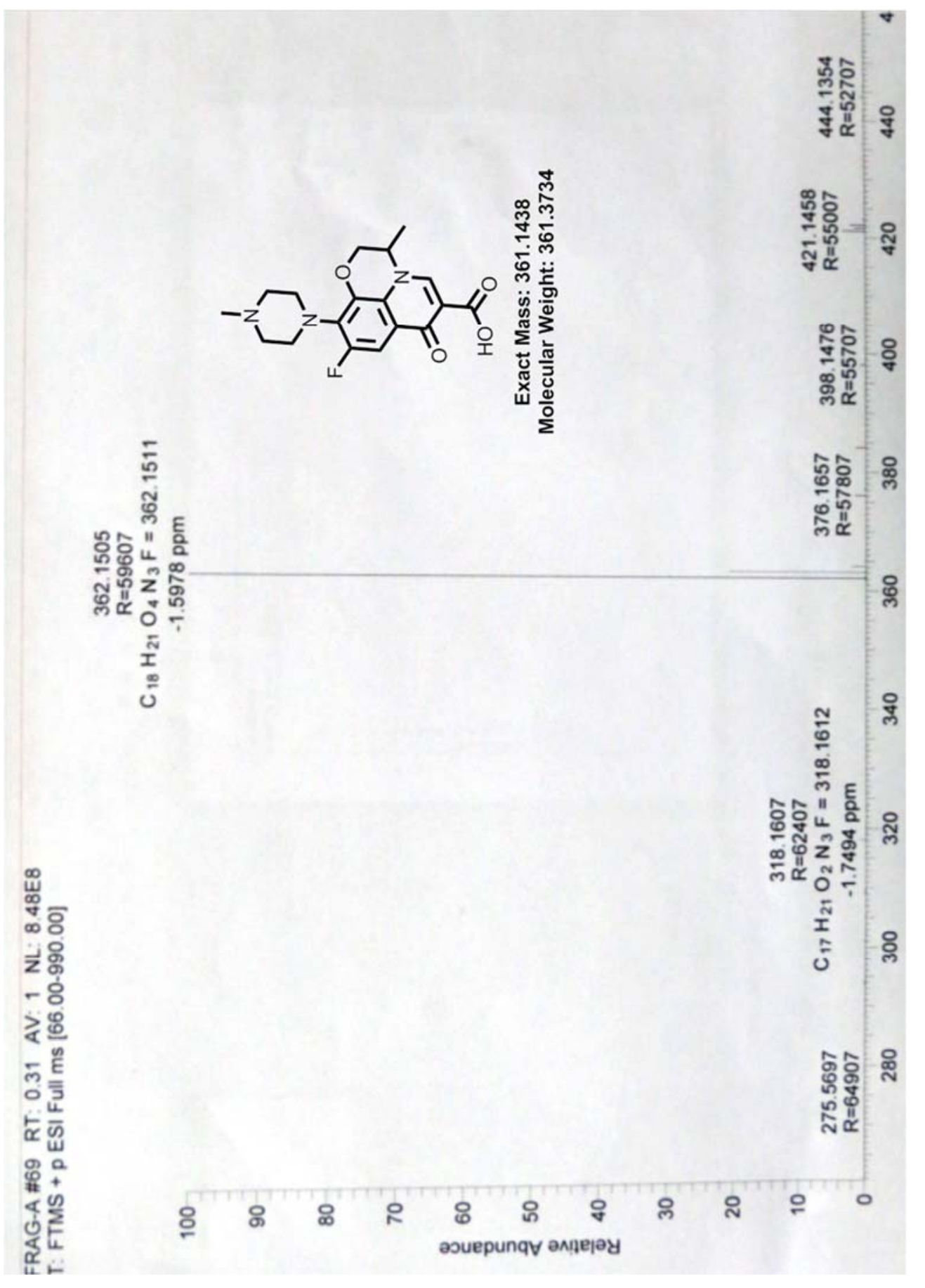

Figure S27. HRMS spectrum of fragment Levofloxacin. 


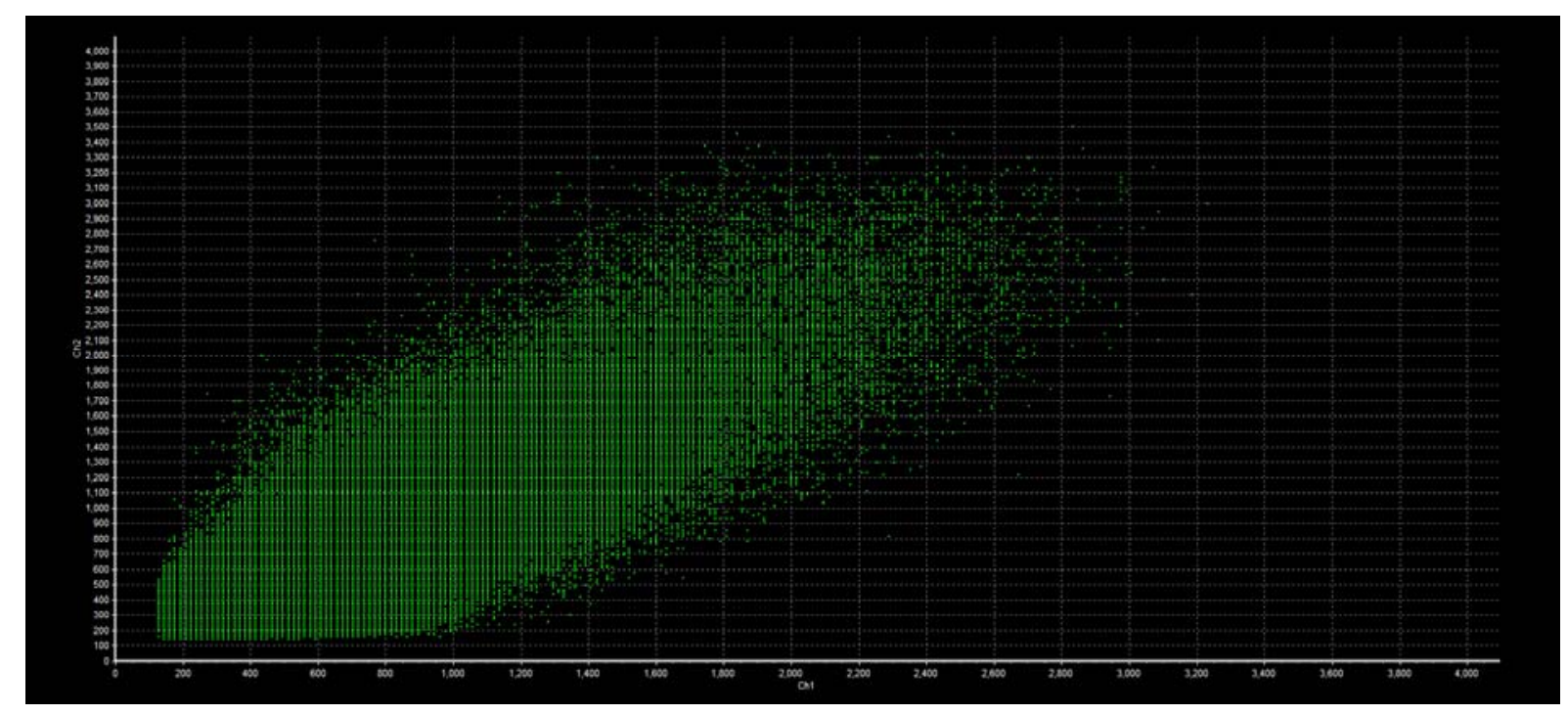

Figure S28. Determination of Pearson coefficient 0.78 with overlap integral 0.93 .
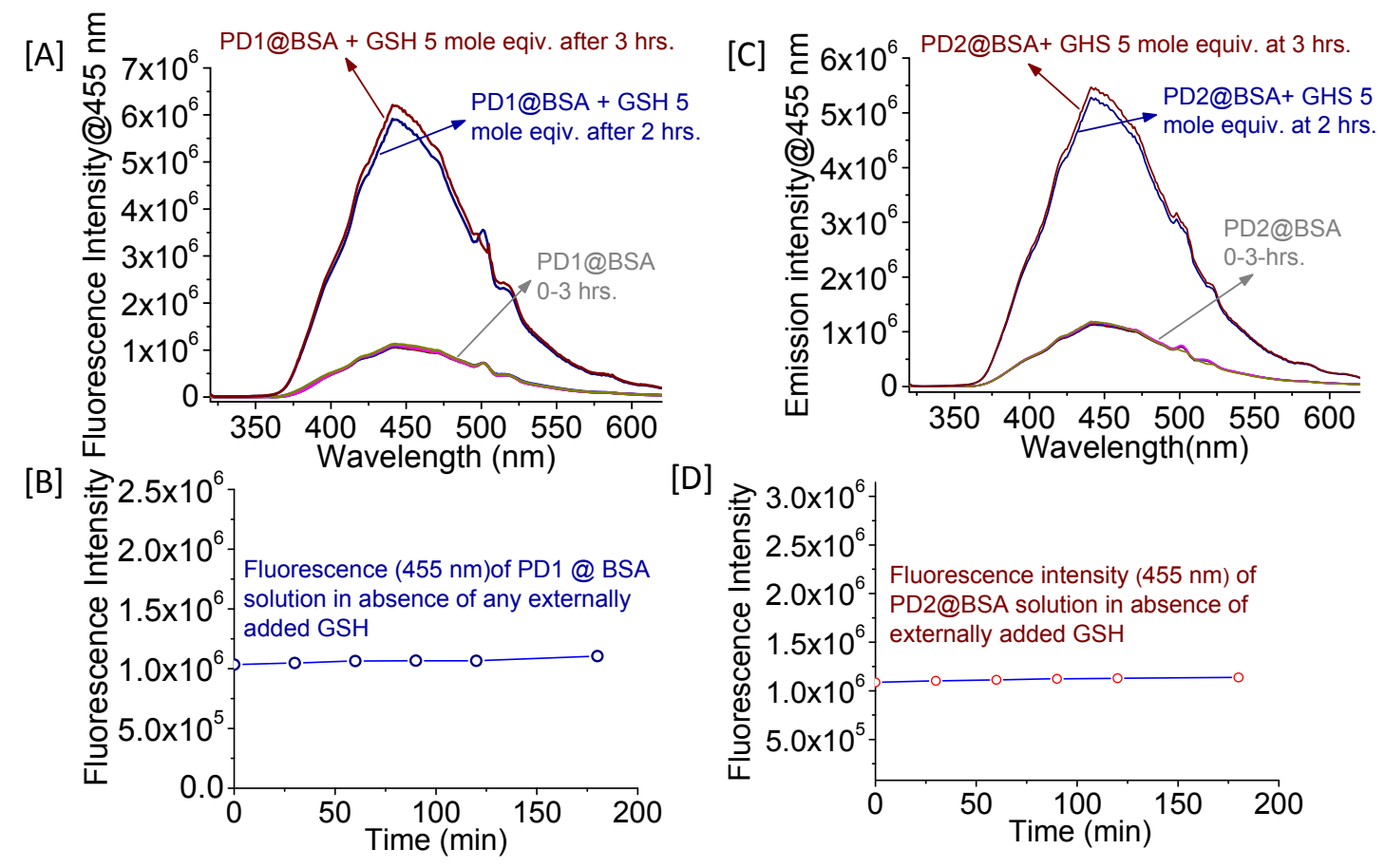

Figure S29. Stability profile of PD1 and PD2 in diluted bovine serum solution, Changes in fluorescence intensity with time for (A \& C) PD1 $\left(3.0 \times 10^{-5} \mathrm{M}\right)$ and $(\mathrm{B} \& \mathrm{D})$ for PD2 $\left(3.0 \times 10^{-5} \mathrm{M}\right)$ in absence and presence of 5 mole equiv. of externally added GSH. 


\section{References:}

S1 Jaina, A. K., Gunda, M. G., Desai, D. C., Borhade, N., Senthilkumar, S. P., Dhiman, M., Mangu, N. K., Mali, S. V., Dubash, N. P., Halder S. et al. (2013) Mutual prodrugs containing bio-cleavable and drug releasable disulfide linkers. Bioorganic Chemistry 49, 40-48.

S2 Kumar, A. (1993) A New Solid Phase Method for the Synthesis of Oligonucleotides with Terminal -3'-Phosphate. Nucleoside and nucleotides 12, 441-447.

S 3 Ravisankar, P., Rani, K. A. , Rao, G. D., Devadasu, CH., (2014) A review on qualitative determination of different members of fluoroquinolone anti-bacterials by hplc methods. J. Chem. Pharm. Sci. 7, 136-47.

S4 Ramu, V., Gill, M. R., Jarman, P. J., Turton, D., Thomas, J. A., Das, A., Smythe, C., (2015) A Cytostatic Ruthenium (II)-Platinum (II) Bis (terpyridyl) Anticancer Complex That Blocks Entry into S Phase by Up-regulating p27KIP1. Chem. Eur. J., 21, 9185 - 9197.

S5 Viola, G., Faccioloa, L., Cantonb, M., Vedaldia, D., Acquaa, F. D.,. Aloisic, G. G, Ameliac, M., Barbafinac, A., Eliseic, F., Latterinic, L., (2004) Photophysical and Phototoxic Properties of the Antibacterial Fluoroquinolones Levofloxacin and Moxifloxacin. Chemistry and Biodiversity, 1, 782-801.

S6 Sheepwash, M. A. L., Ward, T. R., Wang, Y., Bandyopadhyay, S., Mitchell, R. H., Bohne, C. (2003) Mechanistic studies on the photochromism of [e]-annelated dimethyldihydropyrenes. Photochem. Photobiol. Sci., 2, 104-112.

S7 Eaton, D. F. (1989), Luminescence Spectroscopy in Handbook of Organic Photochemistry, ed. J. C. Scaiano, CRC Press, Boca Raton, 1, 231-239. 